Bolm Inst. oceanogr., S Paulo, 28(1):119-165, 1979

\title{
BIONOMIA E CICLO DE VIDA DE UMBRINA CANOSAI, BERG (1895)
}

\author{
ELZA MATTA ZANETI-PRADO
}

\section{Instituto Oceanogräfico da Universidade de são Paulo}

\section{SYNOPSIS}

Ninety-two samples taken during four oceanographic cruises (January/February, April, August, October/November, 1972) provided material to study the bionomics and life history of Umbrina canosai. As many as 1477 specimens were examined to determine individual total length and weight, age (through otoliths readings) sex and maturity. A certain number of ovaries was examined to estimate their fecundity and determine spawning periodicity. Spatial distribution pattern of the species was obtained graphically for the different seasons using demographic isolines. Salinity, temperature and oxygen content of the bottom waters and depth related to the number of individuals caught by unit effort provided information to conclude that $U$. canosai migrates seasonally under the influence of the displacement of Subantarctic waters along the Southern Brazilian coast. A rather different spatial distribution was observed between immature and mature individuals. Spawning occurs throughout August/November and individuals spawn more than once during each spawning season. The recruitment of young specimens occurs during summer-autumn. There is no significant difference in the growth rate for both sexes. The weight/length relationship was significantly different for female and male values. It seems that $U$. canosai is closely associated with the presence of cold waters (below $16^{\circ} \mathrm{C}$ ).

\section{INTRODUÇÃO}

De acordo com Gilbert (1966), o gênero Umbrina ocorre em äguas litorâneas de fundos lodosos e arenosos e inclui 18 ou 19 espécies distribuídas desde o Pacífico Oriental até o Indico Ocidental. Destas, três espécies ocorrem no Atlântico Ocidental: Umbrina coroides, desde o nordeste da Flörida atē o sudeste do Brasil, excluindo o Golfo do México, exceto seu extremo oriental e a costa do Caribe da América Central, desde o Panamá atē o Yucatan; Umbrina broussonnetii, na parte setentrional e ocidental do Caribe, e lmbmina canosai, que está limitada à costa sudeste da América do Sul e, provavelnente, sua PUBL. NO 437 DO INST. OCEAN. DA USP. 
distribuição vai desde o norte da Argentina até as vizinhanças do Rio de Janeiro (Ribeiro, 1915). Fowler (1942) registra apenas U. coroides para a costa do Brasil, enquanto Travassos \& Paiva (1957) assinalam a ocorrência de $U$. coroides e U. broussonnetii.

0 presente estudo refere-se a $U$. canosai na região entre Torres ( $29^{\circ} 21^{\prime} \mathrm{S}$ ) e Maldonado ( $34^{\circ} 54^{\prime} \mathrm{s}$ ) e visa conhecer a bionomia bem como o ciclo de vida da es pécie.

A plataforma continental dessa região, constituỉda principalmente de fundos arenosos e lodosos (Furtado, 1973), of erece condições favoráveis à ocupação da ārea pela espécie.

Sobre a espécie foram realizados apenas estudos preliminares relativos a seu ciclo de vida (Alberdi \& Nani, 1967; Vazzoler, Zaneti \& Kawakami, 1973; Yamaguti, Zaneti \& Kawakami, 1973) e a alguns aspectos do comportamento e alimentação (Vazzoler, 1975; Vazzoler, Kawakami \& Zaneti, 1973), na costa do Rio Grande do Sul.

Assim, justifica-se um estudo mais amplo e detalhado da espécie, uma vez que esta integra uma importante comunidade de peixes demersais da plataforma sul do Brasil.

Na ärea entre Torres e Chuí foi registrada ocorrência de 11 famílias de Elasmobranchii, com 17 gêneros e 30 espécies (Sadowsky, 1971), e de 57 famí1ias de Teleostei, com 93 gêneros e 104 espécies (Menezes, 1971); num levantamento posterior da ārea entre Torres e Maldonado, foram registradas 12 famílias de Elasmobranchii, com 22 gêneros e 40 espécies (Sadowsky, 1973) e 71 famílias de Teleostei, com 121 gêneros e 139 espécies (Benvegnú, 1973).

Os Sciaenidae predominam tanto em número de espécies como em abundância, com ampla distribuição, abrangendo a quase totalidade da plataforma, sendo raramente capturados na faixa de $100-200 \mathrm{~m}$ de profundidade. Constituem-se de 8 gêneros e 10 espécies; dentre estas, Macrodon ancylodon, Micropogon furnieri, Cynoscion striatus e Umbrina canosai, por serem numericamente abundantes, devem desempenhar relevante papel no ecossistema da região. Vazzoler (1975) mostrou que $M$. furnieri, C. striatus e U. canosai exploram a fauna bentônica, utilizando-se de ítens alimentares semelhantes sem todavia ocorrer sobreposição espacial entre elas, amenizando assim a competição alimentar. 
De acordo com Briggs (com. pessoal in: Gilbert, 1966), a amplitude de um número de espécies temperadas-quentes do hemisfério norte parece atingir seu limite sul em torno do Rio de Janeiro, enquanto espécies que são um tanto mais tolerantes a águas frias podem estender-se mais ao sul do Rio da Prata. Umbrina coroides provavelmente pertence ao primeiro grupo, enquanto que outras espécies, tolerando essa variação, pertencem ao segundo grupo. Em alguns casos, aquelas espécies que exibemo primeiro padrão de distribuição são substituídas para o su1, por uma forma relacionada. Podemos supor que $U$. coroides ocorreria em densidades maiores até ao sul do Rio de Janeiro, sendo gradativamente-substituída por $U$. canosai, que atingiria seu máximo de densidade ao sul de $28^{\circ} \mathrm{S}$.

Nos estudos sobre províncias zoogeogräficas, alguns autores admitem como limite entre as Províncias Antilhana e Argentina a latitude de $23^{\circ} \mathrm{S}$; outros, estendem a primeira até $28^{\circ} 28^{\prime} \mathrm{S}$, sendo que ainda existem aqueles que admitem que Uruguai e costa sul do Brasil constituem uma zona de transição.

Boschi (1964), com base na distribuição e freqüência de Penaeidae no Atlântico Sul, observa que Hymenopenaeus muelleri e Artemesia Zonginaris, espécies de águas temperadas, raramente ocorrem ao norte de $28^{\circ} \mathrm{S}$, sendo, na sua opinião, os dois crustáceos mais típicos e importantes da Província Argentina, e considera a zona da costa do Uruguai e sul do Brasil como sendo uma zona de transição. Entretanto, Iwai (1973a) registra a ocorrência das duas espécies atē proximidades de Cabo Frio $\left(23^{\circ} \mathrm{S}\right)$.

As grandes variações sazonais das propriedades hidrográficas nessa ārea, realmente permite-nos considerā-la como uma área de transição. No verão, evidencia-se a importância de um ramo costeiro da Corrente do Brasil na redistribuição das propriedades hidrogrä́ficas, com salinidades e temperaturas a1tas e baixo teor de oxigênio dissolvido, com o aparecimento da Convergência Subtropical ao sul de Conceição. No outono, a circulação geral de superfície apresenta sentido oposto à do verão, com predomínio de águas de baixa salinidade, na faixa até $30 \mathrm{~m}$ de profundidade, oriundas do sul; a região da Convergência está mais ao norte, indicando deslocamento de massa de água com o avanço das águas subantārticas (Corrente das Malvinas). No inverno, acentuase mais essa circulação, com predomínio de águas de baixas salinidades e temperaturas e com alto teor de oxigênio dissolvido, registrando-se grande in- 
fluência das águas do Rio da Prata junto à costa do Rio Grande do Sul e, em meados da primavera, a circulação ainda se mantém semelhante à do inverno, mas as propriedades hidrogräficas jā estão bastante alteradas, com temperaturas e salinidades altas e menor teor de oxigênio dissolvido (Miranda et al., 1973; Mag1iocca, 1973).

Esses conhecimentos contribuíram decisivamente para um entendimento mais aprofundado do comportamento de $U$. canosai, permitindo-nos caracterizá-1a como uma espécie de fauna temperada, estreitamente relacionada aos deslocamentos sazonais das águas subantárticas que invadem a costa sul brasileira. Este estudo permitiu-nos ainda esclarecer vários problemas relativos ao ciclo de vida da espécie, levantados por Alberdi \& Nani (1967), complementando seu conhecimento; a espécie realiza migrações trófica e genética, sendo que sua zona de alimentação localiza-se na região de Mar del Plata e as zonas de reprodução e desenvolvimento na costa sul do Brasil.

\section{MATERIAL E MÉTODOS DE COLETA DE DADOS}

0 material utilizado foi coletado com o N/Oc. "Prof. W. Besnard" durante quatro cruzeiros oceanográficos realizados na plataforma continental do Rio Grande do Sul e Uruguai. Durante os Cruzeiros I (16/1-2/2/72) e II (6$23 / 4 / 72$ ), a ärea amostrada foi entre as latitudes $29^{\circ} 21^{\prime} \mathrm{S}$ (Torres) e $33^{\circ} 44^{\prime} \mathrm{S}$ (Chuí); o Cruzeiro III (3-22/8/72) abrangeu a ärea compreendida entre as 1atitudes $29^{\circ} 21^{\prime} \mathrm{S}$ (Torres) e $34^{\circ} 54^{\prime} \mathrm{S}$ (Maldonado), e no Cruzeiro IV (27/10$3 / 11 / 72$ ) amostrou-se a área entre as latitudes $31^{\circ} 15^{\prime} \mathrm{S}$ (Mostardas) e $34^{\circ} 54^{\prime} \mathrm{S}$ (Maldonado) .

As coletas foram realizadas utilizando-se redes de arrasto-de-porta (otter-traw1), cuja descrição detalhada encontra-se em Iwai (1973b).

As estações oceanogräficas compesca, na plataforma do Rio Grande do Sul, foram fixadas até a isóbata de $100 \mathrm{~m}$, pois trabalho anterior (Vazzoler \& Iwai, 1971) demonstrara ser essa a área onde a fauna de peixes é mais abundante; na plataforma do Uruguai, as estações com pesca abrangeram a área até a isóbata de $200 \mathrm{~m}$, pois não havia informações prévias. O tempo de arrasto foi de 1 hora, com velocidade de, aproximadamente, 3,5 nós/h, em todas as estações. 
Em cada uma delas, foram coletados dados relativos à salinidade, temperatura e teor de oxigênio dissolvido na camada de água próxima ao fundo, profundidade e tipo de fundo ( $T a b$. I A,B,C,D).

No Cruzeiro I, realizado no verão, a espécie ocorreu em 19 das 37 estações oceanográficas onde houve arrasto (Fig. 1). No Cruzeiro II, outono, a espécie ocorreu em 25 das 36 estações oceanogräficas onde efetuou-se arrasto (Fig. 2). No Cruzeiro III, inverno, quando a ārea amostrada foi bem mais ampla, a espécie ocorreu em 33 das 46 estações oceanográficas (Fig. 3). No Cruzeiro IV, primavera, a espécie ocorreu em 14 das 29 estações oceanográficas onde houve arrasto (Fig. 4).

Após a coleta, em cada estação, realizou-se a triagem das diversas espécies de peixes, anotando-se os dados sobre total de quilos e número de indivỉduos, por espēcie.

Os exemplares de $U$. canosai foram manipulados para se obter os dados necessários aos estudos sobre composição da população em classes de comprimento e idade, e ciclo de vida.

De todos os exemplares coletados em cada cruzeiro, foi anotado o comprimento total em milímetros, em classes de 5 em $5 \mathrm{~mm}$, com aproximação para a classe imediatamente inferior. Desse total de exemplares, para cada classe de comprimento de $10 \mathrm{em} 10 \mathrm{~mm}$, foram separados, sempre que possivel, 10 exemplares dos quais foram anotados dados sobre: a) comprimento total (mm); b) peso total (g); c) número de anéis (coleta de escamas e otólitos); d) sexo; e) estádio de maturidade sexual.

Para obtenção de tais dados seguiu-se a metodologia descrita em Vazzoler (1971), considerando-se os quatro estádios de maturidade aí caracterizados:
1) Imaturo
(A) ;
2) Em maturação
(B) ;
3) Maduro
(C); 4) Esvaziado
(D) .

0 número de exemplares dos quais foram anotados os dados acima citados foi o seguinte para cada Cruzeiro:

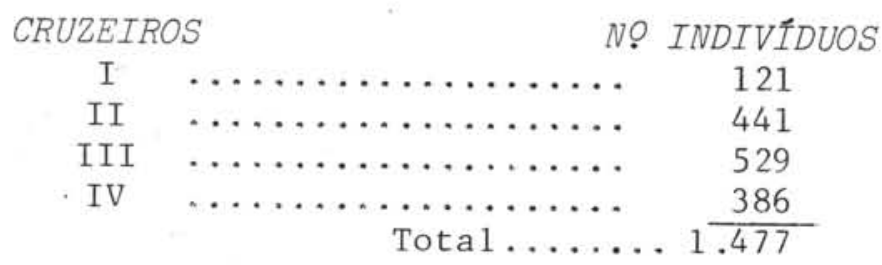


Dados sobre coordenadas das estações, profundidade, salinidade, temperatura e teor de oxigênio na camada de água próxima ao fundo e produção de $U$. canosai

TABELA I A - Cruzei ro I (Verão)

\begin{tabular}{|c|c|c|c|c|c|c|c|c|}
\hline $\begin{array}{c}\text { Estação } \\
(\mathrm{N} O)\end{array}$ & $\begin{array}{l}\text { 1.atitude } \\
\text { (s) }\end{array}$ & $\begin{array}{l}\text { Longitude } \\
\text { (w) }\end{array}$ & $\begin{array}{l}\text { Prof. } \\
\text { (m) }\end{array}$ & $\begin{array}{l}\text { sal. } \\
(0 / 00)\end{array}$ & $\begin{array}{c}\text { Temp. } \\
\left({ }^{\circ} \mathrm{C}\right)\end{array}$ & $\begin{array}{c}\mathrm{O}_{2} \\
(\mathrm{~m} / 1 / 1)\end{array}$ & $\begin{array}{c}\text { PUE } \\
(i \mathrm{nd} / \mathrm{h})\end{array}$ & Obs. \\
\hline 1643 & $33^{\circ} 46^{\prime}$ & $053^{\circ} 17^{\prime}$ & 15 & 31,865 & 22,20 & 3,95 & 4 & \\
\hline 1645 & $34^{\circ} 11^{\circ}$ & $052^{\circ} 19^{\prime}$ & 58 & 33,322 & 14,47 & 4.02 & 4 & * $B T$ \\
\hline 1651 & $32^{\circ} 22^{\prime}$ & $052^{\circ} 47^{\prime}$ & 14 & 31,689 & 24,32 & 4,97 & 110 & * $\mathrm{BT}$ \\
\hline 1652 & $32^{\circ} 58^{\prime}$ & $052^{\circ} 27^{\prime}$ & 12 & 32,689 & 24,92 & 5,24 & 60 & * $\mathrm{BT}$ \\
\hline 1658 & $32^{\circ} 52^{\prime}$ & $051^{\circ} 24^{\prime}$ & 58 & 34,559 & 18,06 & 2,88 & 47 & \\
\hline 16.60 & $32^{\circ} 28^{\prime}$ & $052^{\circ} 15^{\prime}$ & 15 & 32,566 & 24,10 & 4,65 & 238 & * $\mathrm{BT}$ \\
\hline 1661 & $32^{\circ} 05^{\prime}$ & $051^{\circ} 55^{\prime}$ & 13 & 33,273 & 24,72 & 5,70 & 530 & * $\mathrm{BT}$ \\
\hline $166 ?$ & $32^{\circ} 20^{\prime}$ & $051^{\circ} 22^{\prime}$ & 52 & 35,900 & 19,54 & 3,69 & 1 & * \\
\hline 1663 & $32^{\circ} 35^{\prime}$ & $050^{\circ} 32^{\prime}$ & 69 & 35,918 & 17,91 & 4,19 & 43 & \\
\hline 1669 & $31^{\circ} 45^{\prime}$ & $051^{\circ} 26^{\prime}$ & 15 & 33,783 & 23,90 & 4,98 & 3 & * \\
\hline 1670 & $31^{\circ} 30^{\prime}$ & $051^{\circ} 00$ ' & 22 & 34,860 & 24,09 & 5,12 & 19 & \\
\hline 1671 & $31^{\circ} 40^{\circ}$ & $050^{\circ} 40^{\prime}$ & 80 & 35,794 & 16,91 & 4,06 & 4 & \\
\hline 1675 & $31^{\circ} 19^{\prime}$ & $050^{\circ} 22^{\prime}$ & 102 & 35,778 & 16,71 & 4,28 & 12 & \\
\hline 1687 & $30^{\circ} 16^{\prime}$ & $050^{\circ} 09^{\prime}$ & 22 & 35,337 & 24,32 & 4,84 & 28 & BT \\
\hline 1688 & $29^{\circ} 43^{\prime}$ & $048^{\circ} 53^{\prime}$ & 24 & 35,681 & 24,29 & 4,98 & 129 & \\
\hline 1689 & $29^{\circ} 52^{\prime}$ & $049^{\circ} 37^{\prime}$ & 43 & 35,807 & 18,56 & 3,93 & 2 & \\
\hline 1690 & $29^{\circ} 58^{\prime}$ & $049^{\circ} 18^{\prime}$ & 92 & 35,820 & 16,78 & 4,10 & 739 & \\
\hline 1697 & $29^{\circ} 30^{\prime}$ & $048^{\circ} 57^{\prime}$ & 91 & 35,766 & 16,27 & 4,25 & 16 & * \\
\hline 1699 & $29^{\circ} 13^{\circ}$ & $049^{\circ} 35^{\prime}$ & 20 & 35,725 & 24,01 & 4,77 & 35 & \\
\hline 1700 & $28^{\circ} 59^{\prime}$ & $048^{\circ} 42^{\prime}$ & 86 & 35,853 & 15,36 & 3.99 & 34 & \\
\hline
\end{tabular}

TABELA I B - Cruzeiro II (Outono)

\begin{tabular}{|c|c|c|c|c|c|c|c|c|}
\hline $\begin{array}{c}\text { Estaçao } \\
(N O)\end{array}$ & $\begin{array}{c}\text { Latitude } \\
\text { (5) }\end{array}$ & $\begin{array}{l}\text { Longitude } \\
\text { (W) }\end{array}$ & $\begin{array}{c}\text { Prof. } \\
(\mathrm{m})\end{array}$ & $\begin{array}{l}\text { Sal. } \\
(\% / 00)\end{array}$ & $\begin{array}{c}\text { Temp. } \\
\left({ }^{\circ} \mathrm{C}\right)\end{array}$ & $\begin{array}{c}\mathrm{O}_{2} \\
(\mathrm{~m} 1 / 1) \\
\end{array}$ & $\begin{array}{c}\text { PUE } \\
(\text { ind/h) }\end{array}$ & Obs. \\
\hline 1705 & $29^{\circ} 23^{\prime}$ & $049^{\circ} 16^{\prime}$ & 47 & 35,400 & 23,45 & 4,43 & 260 & \\
\hline 1706 & $29^{\circ} 33^{\circ}$ & $048^{\circ} 57^{\prime}$ & 96 & 35,943 & 17,59 & 4,70 & 77 & \\
\hline 1713 & $30^{\circ} 01$ ' & $049^{\circ} 19^{\prime}$ & 92 & 35,885 & 17,22 & 4,16 & 5 & * \\
\hline 1714 & $29^{\circ} 52^{\prime}$ & $049^{\circ} 37^{\prime}$ & 43 & 34,917 & 22,87 & 5,15 & 228 & \\
\hline 1716 & $30^{\circ} 15^{\prime}$ & $050^{\circ} 09^{\prime}$ & 26 & 34,717 & 22,61 & 4,91 & 2 & * \\
\hline 1717 & $30^{\circ} 26^{\prime}$ & $049^{\circ} 47^{\prime}$ & 75 & 35,864 & 18,63 & 3,37 & 6 & * \\
\hline 1723 & $30^{\circ} 55^{\prime}$ & $050^{\circ} 11^{\prime}$ & 90 & 35,788 & 16,79 & 4,51 & 4 & \\
\hline 1725 & $31^{\circ} 09^{\prime}$ & $050^{\circ} 43^{\prime}$ & 21 & 34,832 & 22,28 & 4,78 & 2 & * \\
\hline 1726 & $31^{\circ} 13^{\prime}$ & $050^{\circ} 35^{\prime}$ & 57 & 35,863 & 17,84 & 3,87 & 160 & \\
\hline 1727 & $31^{\circ} 19^{\prime}$ & $050^{\circ} 22^{\prime}$ & 100 & 35,857 & 17,54 & 3,83 & 153 & \\
\hline 1730 & $31^{\circ} 50^{\circ}$ & $050^{\circ} 21^{\prime}$ & 116 & 35,905 & 17,79 & 4,18 & 70 & \\
\hline 1731 & $31^{\circ} 36^{\prime}$ & $050^{\circ} 38^{\prime}$ & 80 & 35,954 & 18,76 & 4,10 & 190 & \\
\hline 1734 & $31^{\circ} 58^{\prime}$ & $051^{\circ} 00^{\prime}$ & 56 & 35,298 & 22,58 & 3,95 & 852 & \\
\hline 1735 & $32^{\circ} 10^{\prime}$ & $050^{\circ} 35^{\prime}$ & 84 & 36,062 & 18,41 & 4,55 & 19 & \\
\hline 1737 & $36^{\circ} 46^{\prime}$ & $053^{\circ} 16^{\prime}$ & 15 & 33,008 & 19,86 & 4,60 & 17 & \\
\hline 1738 & $33^{\circ} 58^{\circ}$ & $052^{\circ} 50^{\prime}$ & 29 & 32,784 & 20,40 & 4,83 & 490 & \\
\hline 1739 & $34^{\circ} 09^{\circ}$ & $052^{\circ} 16^{\circ}$ & 69 & 32,699 & 20,12 & 4,72 & 22 & \\
\hline 1743 & $33^{\circ} 50^{\circ}$ & $051^{\circ} 51^{\prime}$ & 65 & 34,454 & 18,59 & 5,41 & 886 & \\
\hline 1744 & $33^{\circ} 37^{\prime}$ & $052^{\circ} 16^{\prime}$ & 52 & 32,580 & 19,85 & 5,29 & 123 & \\
\hline 1747 & $33^{\circ} 15^{\prime}$ & $051^{\circ} 56^{\prime}$ & 56 & 33,996 & 19,68 & 3,47 & 78 & \\
\hline 1748 & $33^{\circ} 28^{\prime}$ & $051^{\circ} 30^{\prime}$ & 78 & 36,037 & 21,22 & 4,81 & 368 & \\
\hline 1751 & $33^{\circ} 10^{\prime}$ & $050^{\circ} 50^{\prime}$ & 100 & 35,968 & 19,28 & 3,49 & 45 & \\
\hline 1752 & $32^{\circ} 53^{\circ}$ & $051^{\circ} 22^{\prime}$ & 60 & 34,456 & 20,36 & 4,58 & 107 & \\
\hline 1753 & $32^{\circ} 40^{\prime}$ & $051^{\circ} 51^{\prime}$ & 27 & 32,856 & 20,85 & 5,40 & 2 & * \\
\hline 1736 & $32^{\circ} 23^{\circ}$ & $051^{\circ} 20^{\prime}$ & 57 & 33,257 & 19,78 & 4,40 & 250 & \\
\hline
\end{tabular}


TABELA I C - Cruzeiro III (Inverno)

\begin{tabular}{|c|c|c|c|c|c|c|c|c|}
\hline 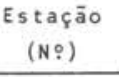 & $\begin{array}{l}\text { Latitude } \\
\text { (s) }\end{array}$ & $\begin{array}{l}\text { Longi tude } \\
\text { (W) }\end{array}$ & $\begin{array}{l}\text { Prof. } \\
(\mathrm{m})\end{array}$ & $\begin{array}{l}\text { Sal. } \\
(\% / 00)\end{array}$ & $\begin{array}{l}\text { Temp. } \\
\left({ }^{\circ} \mathrm{C}\right)\end{array}$ & $\begin{array}{c}0_{2} \\
(\mathrm{~m} 1 / 1) \\
\end{array}$ & $\begin{array}{c}\text { PUE } \\
(\mathrm{ind} / \mathrm{h}) \\
\end{array}$ & obs. \\
\hline 1851 & $29^{\circ} 51^{\prime}$ & $049^{\circ} 37^{\prime}$ & 40 & 32,487 & 16,00 & 6,17 & 4 & B T * \\
\hline 1852 & $29^{\circ} 43^{\prime}$ & $049^{\circ} 55^{\prime}$ & 24 & 31,506 & 14,71 & 5,07 & 99 & \\
\hline 1853 & $30^{\circ} 14^{\prime}$ & $050^{\circ} 09^{\prime}$ & 21 & 31,382 & 14,31 & 5,73 & 5 & \\
\hline 1854 & $30^{\circ} 27^{\prime}$ & $049^{\circ} 47^{\prime}$ & 60 & 32,153 & 15,10 & 5,20 & 20 & \\
\hline 1855 & $30^{\circ} 37^{\prime}$ & $049^{\circ} 25^{\prime}$ & 150 & 35,696 & 16,22 & 4,16 & 205 & \\
\hline 1859 & $31^{\circ} 03^{\prime}$ & $049^{\circ} 46^{\prime}$ & 144 & 35,760 & 18,86 & 4,63 & 185 & \\
\hline 1860 & $30^{\circ} 50^{\circ}$ & $050^{\circ} 06^{\prime}$ & 78 & 34,379 & 17,02 & 4,81 & 59 & \\
\hline 1862 & $31^{\circ} 09^{\prime}$ & $050^{\circ} 43^{\prime}$ & 20 & 26,839 & 13,01 & 6,25 & 7 & \\
\hline 1863 & $31^{\circ} 15^{\prime}$ & $050^{\circ} 27^{\prime}$ & 85 & 34,676 & 17,11 & 5,78 & 285 & \\
\hline 1864 & $31^{\circ} 24^{\prime}$ & $050^{\circ} 12^{\prime}$ & 127 & 35,843 & 17,31 & 4,12 & 4 & * \\
\hline 1866 & $35^{\circ} 00^{\prime}$ & $054^{\circ} 50^{\prime}$ & 23 & 32,841 & 10,83 & 5,23 & 4 & \\
\hline 1876 & $34^{\circ} 35^{\prime}$ & $053^{\circ} 58^{\prime}$ & 22 & 33,257 & 10,86 & 5,28 & 13 & \\
\hline 1878 & $34^{\circ} 15^{\prime}$ & $053^{\circ} 08^{\prime}$ & 31 & 33,344 & 10,59 & 5,42 & 6 & \\
\hline 1879 & $34^{\circ} 25^{\prime}$ & $052^{\circ} 47^{\prime}$ & 49 & 33,408 & 10,47 & 5,53 & 4 & \\
\hline 1885 & $34^{\circ} 01^{\prime}$ & $052^{\circ} 44^{\prime}$ & 28 & 33,087 & 10,87 & 5,68 & 502 & \\
\hline 1886 & $34^{\circ} 45^{\prime}$ & $053^{\circ} 16^{\prime}$ & 16 & 29,910 & 11,70 & 6,11 & 2 & \\
\hline 1887 & $34^{\circ} 20^{\prime}$ & $052^{\circ} 46^{\prime}$ & 16 & 28,491 & 12,24 & 5,61 & 43 & \\
\hline 1888 & $33^{\circ} 36^{\prime}$ & $052^{\circ} 18^{\prime}$ & 42 & 33,247 & 11,43 & 5,20 & 439 & \\
\hline 1889 & $33^{\circ} 50^{\prime}$ & $051^{\circ} 50^{\prime}$ & 75 & 34,084 & 12,17 & 5,42 & 152 & \\
\hline 1892 & $33^{\circ} 29^{\prime}$ & $051^{\circ} 21^{\prime}$ & 86 & 34,658 & 14,41 & 5,02 & 262 & \\
\hline 1893 & $33^{\circ} 14^{\prime}$ & $051^{\circ} 48^{\prime}$ & 45 & 33,192 & 11,94 & 5,15 & 2556 & \\
\hline 1894 & $32^{\circ} 58^{\prime}$ & $052^{\circ} 30^{\prime}$ & 13 & 27,879 & 12,80 & 5,96 & 45 & \\
\hline 1895 & $32^{\circ} 28^{\prime}$ & $052^{\circ} 15^{\prime}$ & 14 & 28,307 & 12,96 & 5,31 & 55 & \\
\hline 1896 & $32^{\circ} 43^{\prime}$ & $051^{\circ} 44^{\prime}$ & 35 & 33,562 & 13,46 & 4,59 & 1955 & \\
\hline 1897 & $32^{\circ} 58^{\prime}$ & $051^{\circ} 14^{\prime}$ & 64 & 34,173 & 14,34 & 4,60 & 88 & \\
\hline 1898 & $33^{\circ} 08^{\prime}$ & $050^{\circ} 55^{\prime}$ & 100 & 35,033 & 15,82 & 4,57 & 4 & $\mathrm{BT} *$ \\
\hline 1902 & $32^{\circ} 38^{\prime}$ & $050^{\circ} 46^{\prime}$ & 75 & 35,136 & 18,18 & 4,41 & 2 & * \\
\hline 1905 & $31^{\circ} 45^{\prime}$ & $051^{\circ} 26^{\prime}$ & 15 & 30,825 & 14,55 & 5,17 & 8 & \\
\hline 1906 & $31^{\circ} 54^{\prime}$ & $051^{\circ} 05^{\prime}$ & 50 & 35,652 & 17,93 & 4,04 & 850 & \\
\hline 1907 & $32^{\circ} 07^{\prime}$ & $050^{\circ} 40^{\prime}$ & 91 & 35,976 & 18,34 & 4,10 & 48 & \\
\hline 1910 & $31^{\circ} 48^{\prime}$ & $050^{\circ} 22^{\prime}$ & 107 & 35,806 & 17,50 & 4,66 & 2 & * \\
\hline 1911 & $31^{\circ} 38^{\prime}$ & $050^{\circ} 43^{\prime}$ & 70 & 35,685 & 17,63 & 4,33 & 62 & \\
\hline 1912 & $31^{\circ} 27^{\prime}$ & $051^{\circ} 04^{\prime}$ & 21 & 29,941 & 14,86 & 5,77 & 10 & \\
\hline
\end{tabular}

TABELA I D - Cruzeiro IV (Primavera)

\begin{tabular}{|c|c|c|c|c|c|c|c|c|}
\hline $\begin{array}{c}\text { Es t ação } \\
\text { (N@) }\end{array}$ & $\begin{array}{l}\text { Latitude } \\
\text { (s) }\end{array}$ & $\begin{array}{l}\text { Longitude } \\
\text { (W) }\end{array}$ & $\begin{array}{c}\text { Prof. } \\
(\mathrm{m})\end{array}$ & $\begin{array}{l}\text { Sal. } \\
(\% / 00)\end{array}$ & $\begin{array}{l}\text { Temp. } \\
\left({ }^{\circ} \mathrm{C}\right)\end{array}$ & $\begin{array}{c}\mathrm{O}_{2} \\
(\mathrm{~m} 1 / 1)\end{array}$ & $\begin{array}{c}\text { PUE } \\
(\mathrm{ind} / \mathrm{h})\end{array}$ & obs. \\
\hline 1913 & $31^{\circ} 27^{\prime}$ & $051^{\circ} 05^{\prime}$ & 19 & 34,845 & 18,30 & 4,61 & 18 & \\
\hline 1915 & $35^{\circ} 00^{\prime}$ & $054^{\circ} 50^{\prime}$ & 25 & 28,236 & 15,49 & 5,44 & 23 & \\
\hline 1924 & $34^{\circ} 34^{\prime}$ & $053^{\circ} 56^{\prime}$ & 22 & 32,122 & 13,26 & 5,86 & 949 & \\
\hline 1925 & $34^{\circ} 04^{\prime}$ & $053^{\circ} 29^{\prime}$ & 20 & 31,669 & 12,35 & 5,55 & 298 & \\
\hline 1926 & $34^{\circ} 14^{\prime}$ & $053^{\circ} 08^{\prime}$ & 31 & 32,826 & 10,50 & 5,32 & 254 & \\
\hline 1931 & $33^{\circ} 47^{\prime}$ & $053^{\circ} 16^{\prime}$ & 19 & 30,845 & 13,95 & 5,63 & 13 & \\
\hline 1932 & $32^{\circ} 21^{\prime}$ & $052^{\circ} 48^{\prime}$ & 15 & 30,720 & 14,25 & 6,26 & 15 & \\
\hline 1933 & $33^{\circ} 35^{\prime}$ & $052^{\circ} 19^{\prime}$ & 38 & 32,234 & 11,45 & 5,86 & 993 & \\
\hline 1936 & $33^{\circ} 13^{\prime}$ & $051^{\circ} 58^{\prime}$ & 51 & 32,874 & 10,31 & 5,35 & 23 & \\
\hline 1938 & $32^{\circ} 28^{\prime}$ & $052^{\circ} 14^{\prime}$ & 15 & 30,304 & 15,89 & 5,52 & 29 & \\
\hline 1939 & $32^{\circ} 29^{\prime}$ & $051^{\circ} 50^{\prime}$ & 26 & 31,171 & 14,43 & 3,22 & 872 & \\
\hline 1940 & $32^{\circ} 51^{\prime}$ & $051^{\circ} 26^{\prime}$ & 60 & 33,099 & 10,96 & 4,41 & 51 & \\
\hline 1941 & $32^{\circ} 28^{\prime}$ & $051^{\circ} 07^{\prime}$ & 60 & 35,244 & 16,68 & 3,68 & 481 & \\
\hline 1942 & $32^{\circ} 17^{\prime}$ & $051^{\circ} 31^{\prime}$ & 28 & 32,059 & 14,90 & 5,89 & 170 & \\
\hline
\end{tabular}

obs.: - * Os exemplares destas estaçōes oceanogräficas estão na coleçào do Museu de Zoologia da USP; portanto, näo foi possivel a utilizaçao dos mesmos no estudo de ciclo de vida, mas no estudo de bionomia os exemplares capturados com rede tipo "beam-trawl" (BT), no veräo, e todos aqueles coletados com "otter-trawl" (OT) utilizados na coleção foram englobados para uma discussāo mais
ampla e completa sobre o comportamento da espécie. 


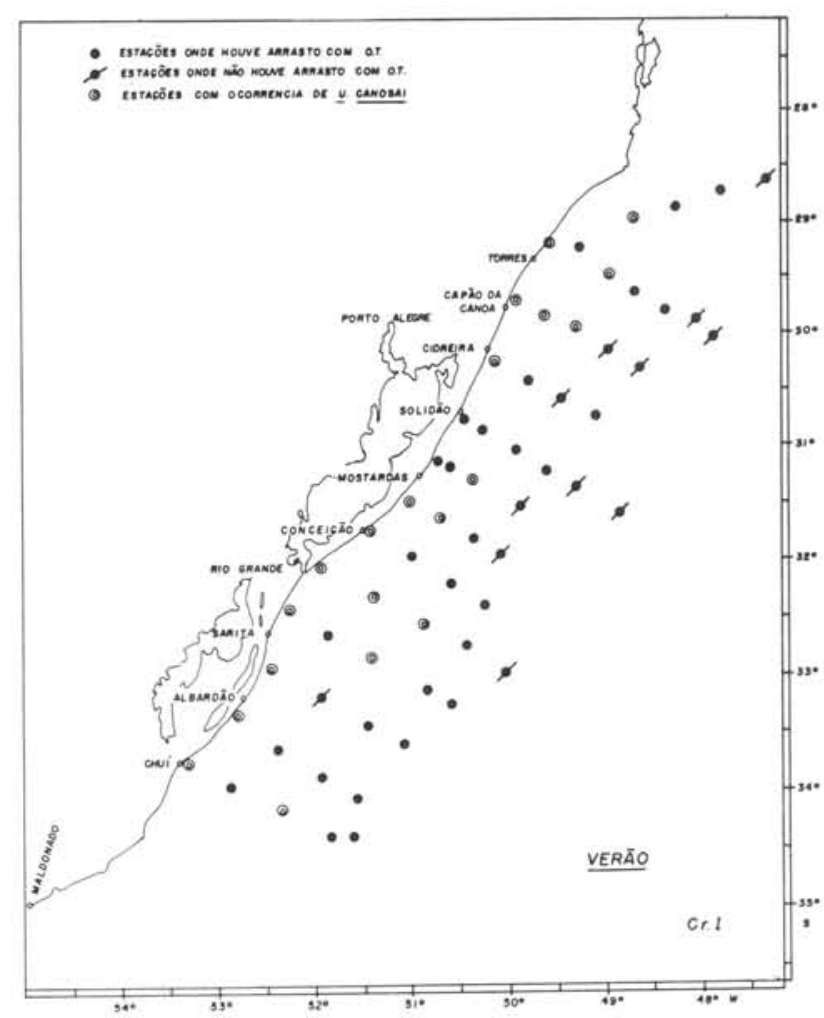

Fig. 1 - Localização das estações oceanogrắficas, com indi cação de ocorrência de $U$. canosai, no verão.

Fig. 2 - Localização das estações oceanogrä́ficas, com indicação de ocorrência de $U$. canosai, no outono.

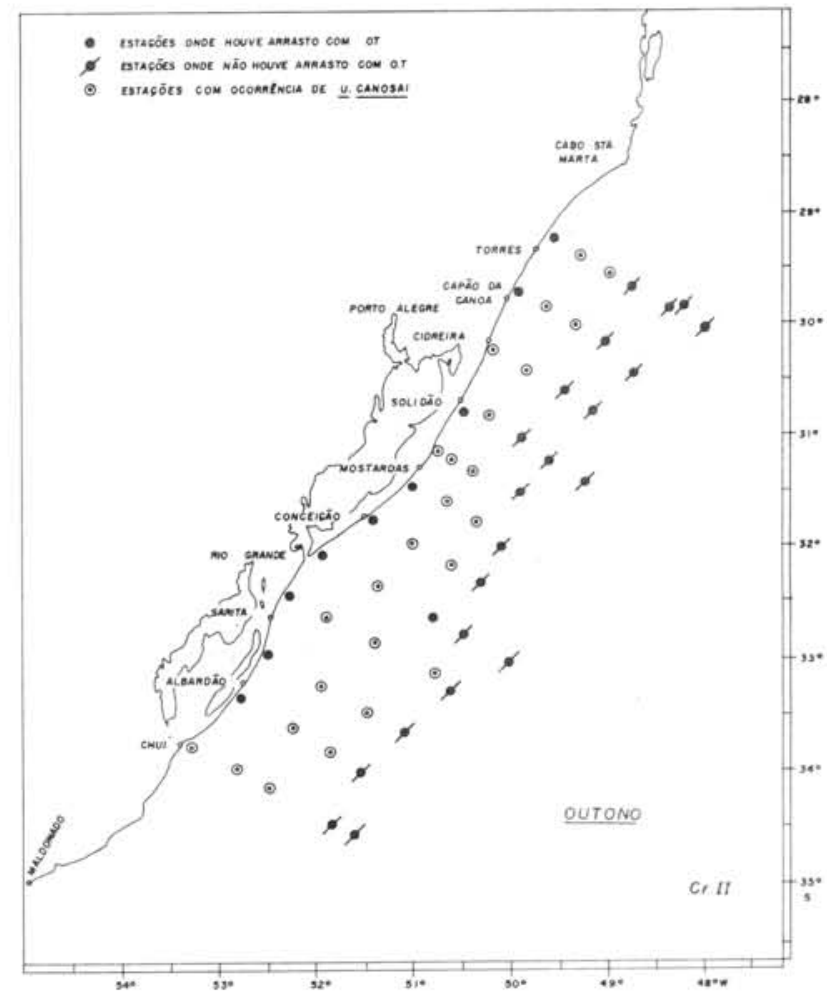




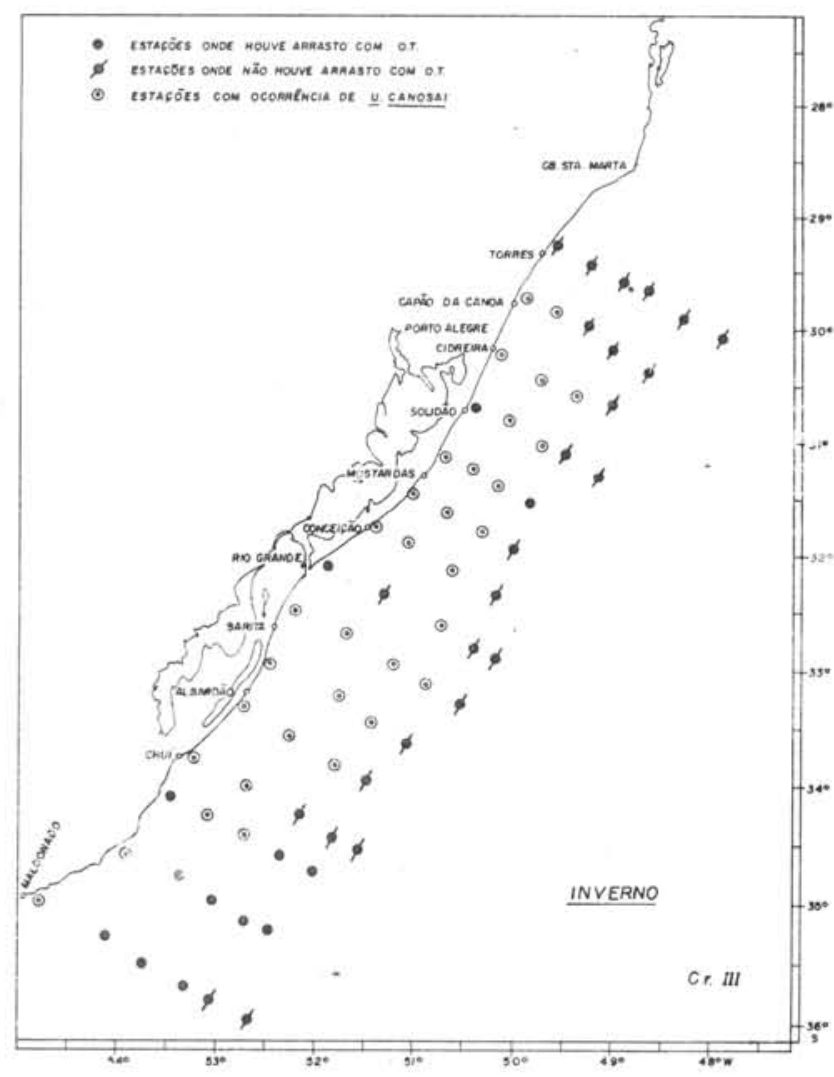

Fig. 3 - Localização das estações oceanogrăficas, com indicação de ocorrência de $U$. canosai, no inverno.

Fig. 4 - Localização das es tações oceanogrä́ficas, com indicação de ocorrência de $U$. canosai, na primavera.

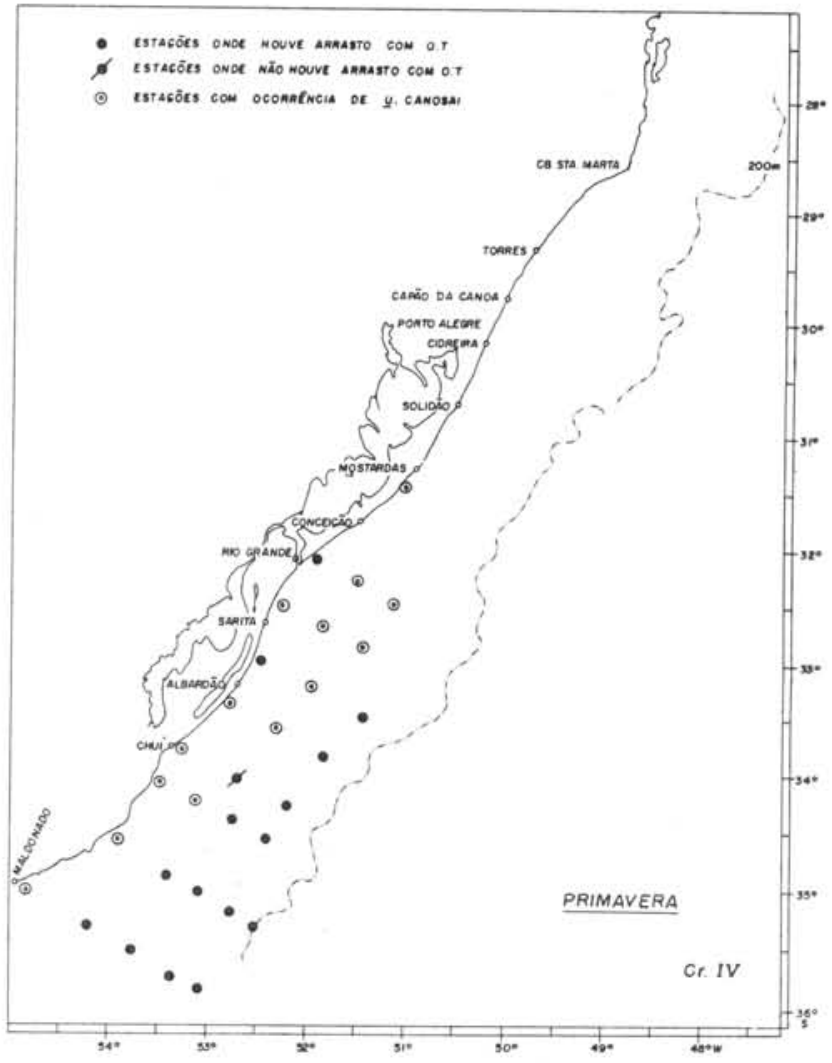


De 34 fêmeas coletadas durante os Cruzeiros III e IV, que se apresentavam em fase final de maturação (final de B), retirou-se os ovários para estudos sobre o tipo de desova e fecundidade. Estes foram pesados em balança Mett1er P-1200, com aproximação até centésimo de grama. Após a pesagem, para estimativa da fecundidade, seguiu-se o procedimento descrito em Vazzoler $(1963 a)$.

Para se obter dados sobre nümero de anéis, foram retirados escamas e otólitos, os quais foram colocados em envelopes plásticos e etiquetados com o número da amostra e do exemplar, para tratamento posterior. As escamas foram montadas entre lâminas de vidro e observadas sob estereomicroscópio Wild M-5, segundo descrito em Vazzoler (1971). A leitura dos anéis dos otólitos foi feita após os mesmos serem queimados em chama de bico de Bunsen até adquirirem cor de caramelo (Christensen, 1964); após esfriarem, foram quebrados numa secção transversal mediana e colocados em recipiente de fundo preto, imersos em xilol, orientados sobre um suporte metálico com a face quebrada voltada para cima, e iluminados com luz direta sob estereomicroscópio Wild M-5. Assim observados, os mesmos apresentavam faixas concêntricas translúcidas amareladas (anēis), que foram contadas. Após leituras preliminares das escamas e dos otólitos, e de comparar os resultados, inclusive com aqueles obtidos para a espécie por Alberdi \& Nani (1967), optamos pela utilização dos otólitos para a determinação do número de anéis. Foram analisados 1477 otólitos, no total.

\section{MÉTODOS DE ANÁLISE DOS DADOS}

Os dados de $U$. canosai, relativos a cada um dos aspectos considerados, foram analisados inicialmente para duas subäreas: $29^{\circ} 21^{\prime} \mathrm{S}-33^{\circ} \mathrm{S}$ e $33^{\circ} \mathrm{S}-34^{\circ} 54^{\prime} \mathrm{S}$. Os resultados indicaram homogeneidade dentro da ärea total estudada, motivo pelo qual passamos a tratar os dados em conjunto.

Para análise da composição da população em classes de comprimento, por estação do ano (Cruzeiro) e para o total coletado, foram obtidas as distribuições de freqüência (\%) de classes de comprimento, de $10 \mathrm{em} 10 \mathrm{~mm}$. Os resultados foram lançados em gráficos (histogramas) o que permite visualizar a variação na composição em classes de comprimento no tempo, oferecendo, ainda, informações sobre a época de recrutamento (Figs 5, 7A). 


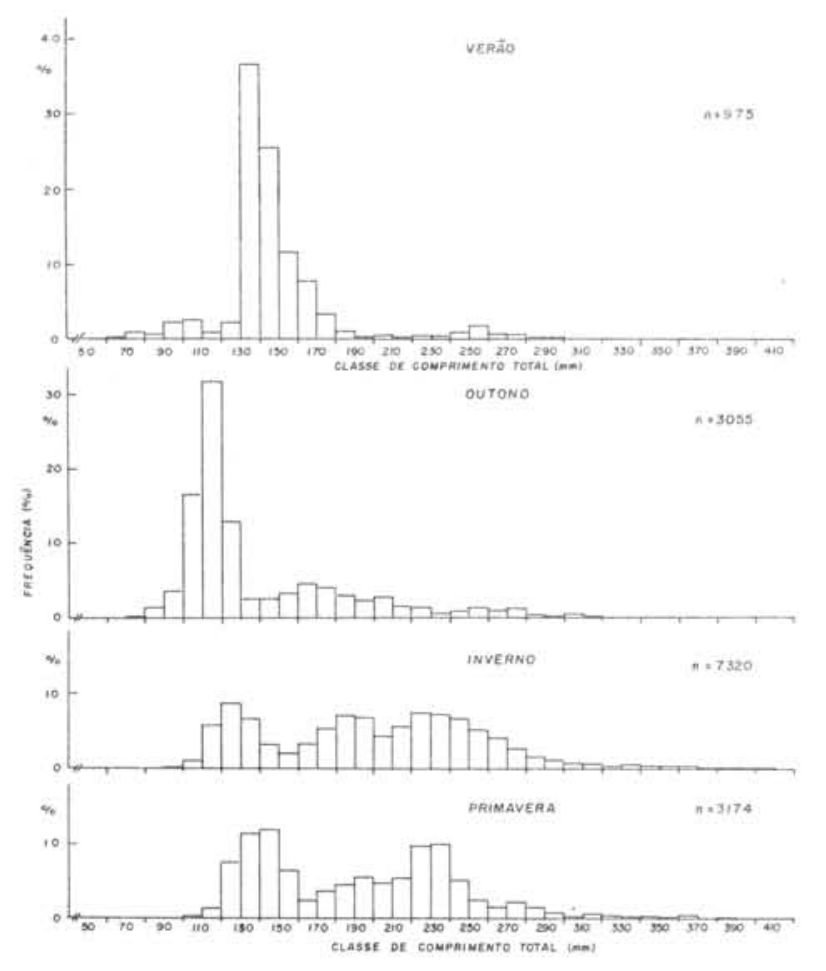

Fig. 5 - Histogramas de distribuição de freqüência de classes de comprimento total de U. canosai, para sexos grupados, por estação do ano.

Com os dados sobre comprimento total e número de anéis das subamostras do total coletado, por estação do ano e para o período global, calculou-se as distribuições de freqüência dos diferentes grupos de número de anēis por classe de comprimento, de $10 \mathrm{em} 10 \mathrm{~mm}$. A partir destas proporções, distribuiuse o número total de indivíduos medidos em cada classe de comprimento, por grupo de número de anéis. A seguir, calculou-se as distribuições de freqüência relativa dos grupos de anéis, por estação do ano e para todo o período (Figs 6,7B).

Para cada estação do ano, foi obtido o nümero de fêmeas e de machos e calculadas suas freqüências relativas, sendo os valores lançados em gräficos (Fig. 8); aplicou-se o teste do $x^{2}$ para verificar se ocorria ou não, entre as freqüências de fêmeas e machos, diferença significativa, obtendo-se os valores mostrados na Tabela II.

Para estimar o comprimento médio do início da primeira maturação sexual, machos e fêmeas foram grupados, separadamente, em imaturos (estádio A) e maturos (estádios $B+C+D$ ), considerando-se todo o período estudado. Obteve-se as distribuições de freqüência relativa de fêmeas e machos, por classe de comprimento de $15 \mathrm{em} 15 \mathrm{~mm}$; os resultados referentes à freqüência de in- 

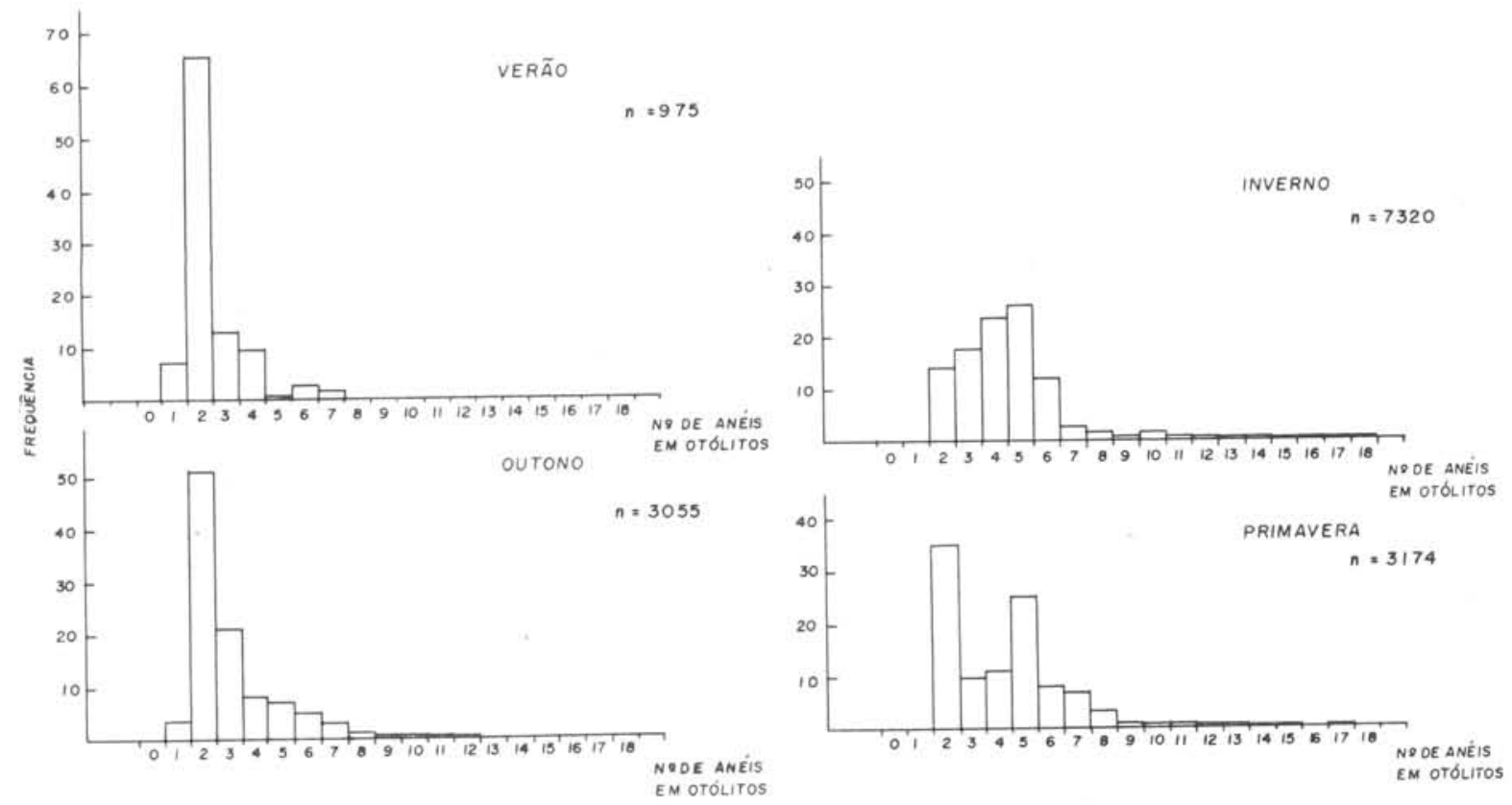

Fig. 6 - Histogramas de distribuição de freqüência de grupos de n? de anēis (idade) de $U$. canosai, para sexos grupados, parao período estudado.
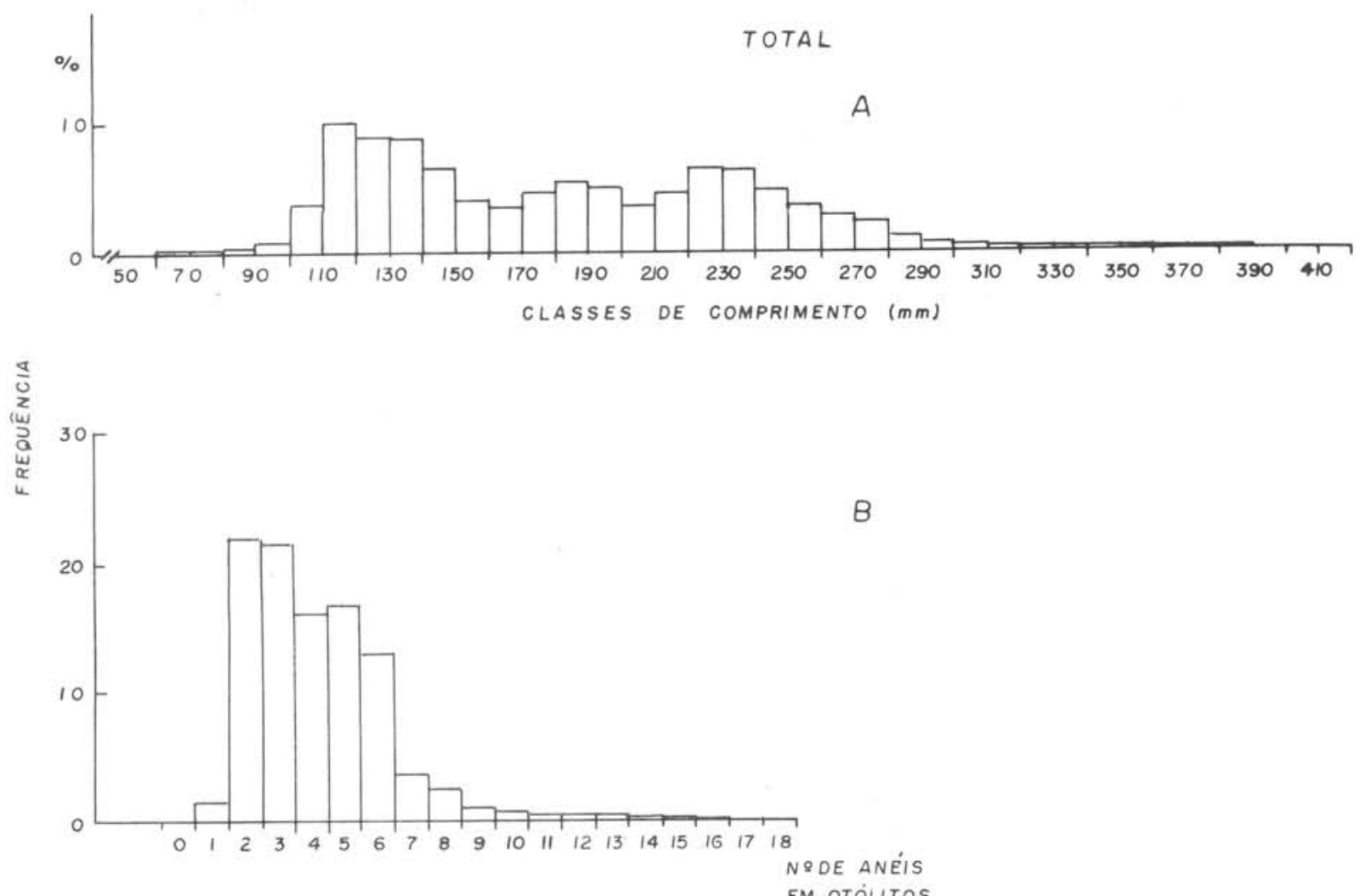

Fig. 7 - Histograma de distribuição de freqüência de classes de comprimento total (A) e de grupos de n? de anéis (idade) (B) de U. canosai, para sexos grupados, para o período estudado. 


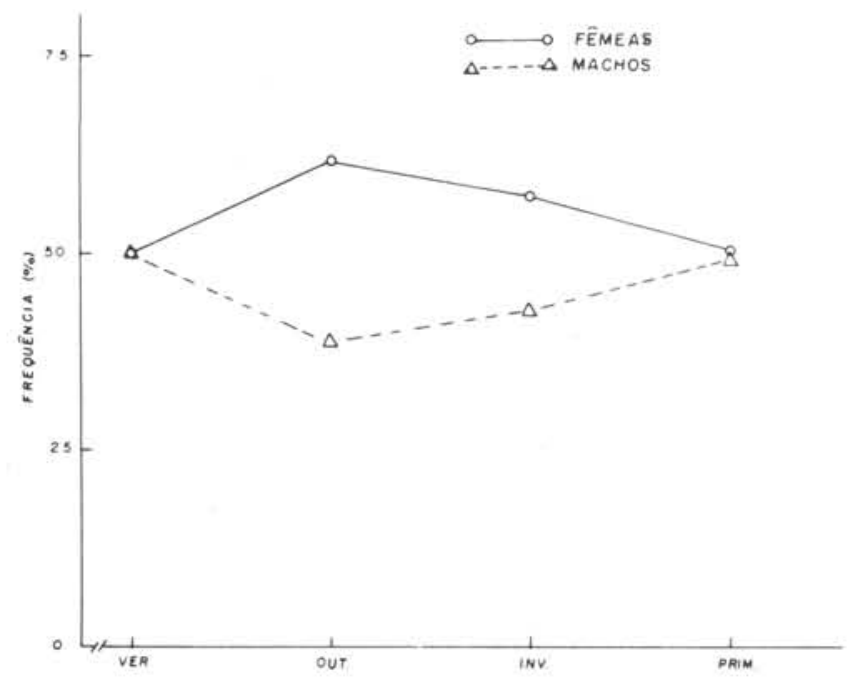

Fig. 8 - Distribuição de freqüência de machos e fêmeas de U. canosai, por estação do ano.

TABELA II - Resultados do teste do $x^{2}$ aplicado às freqüências de fêmeas e machos, durante as estações do ano

\begin{tabular}{|l|c|c|c|}
\hline $\begin{array}{c}\text { ESTAÇAO } \\
\text { DOANO }\end{array}$ & N: $\sigma^{*}$ & N\% & $x^{2}$ \\
\hline VERAO & 37 & 37 & - \\
\hline OUTONO & 120 & 189 & $15,40^{*}$ \\
\hline INVERNO & 191 & 261 & $10,84^{*}$ \\
\hline PRIMAVERA & 138 & 139 & 0,007 \\
\hline$*$ - Significativo aO nivel de $0,1 \%$ & \\
\hline
\end{tabular}

divíduos adultos, por sexo, foram lançados em gräficos (Figs 9A, B) e a mediana determinada graficamente. Esse valor corresponde a uma estimativa do comprimento médio do início da primeira maturação sexual ( $\left.\overline{\mathrm{L}}_{\mathrm{m}}\right)$, ou seja, o comprimento em que $50 \%$ dos indivíduos da população iniciam seu processo de maturação sexual. Também foi estimado graficamente o comprimento em que todos os indivíduos da população estão maturos ( $\left.\mathrm{L}_{100 \%}\right)$.

Para obter informações sobre o período em que ocorre entrada de indivíduos jovens na população (recrutamento), foram calculadas as freqüências de indivíduos imaturos e maturos por estação do ano, sendo os resultados lançados em gräfico (Fig. 10).

Com os dados sobre os quatro estádios de maturidade sexual, foram obtidas as distribuições de freqüência relativa (\%) dos mesmos, por estação do ano; os resultados foram lançados em gräfico e a observação deste fornece informações sobre a época de desova da espécie (Fig. 11). 

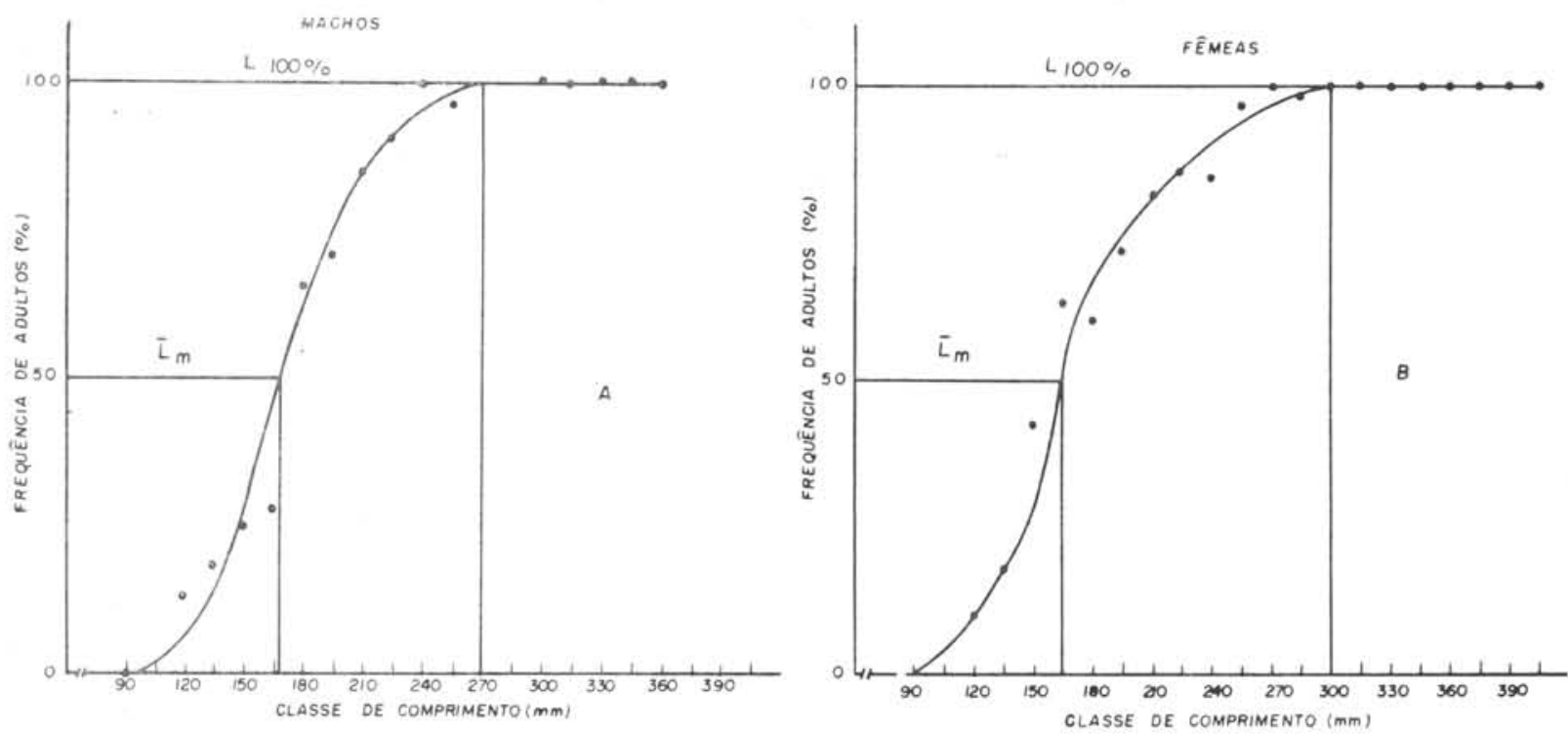

Fig. 9 - Distribuições de freqüência de machos (A) e de fêmeas (B) adultos (estä́dio B C D) de U. canosai, por classe de comprimento, para o período estudado.

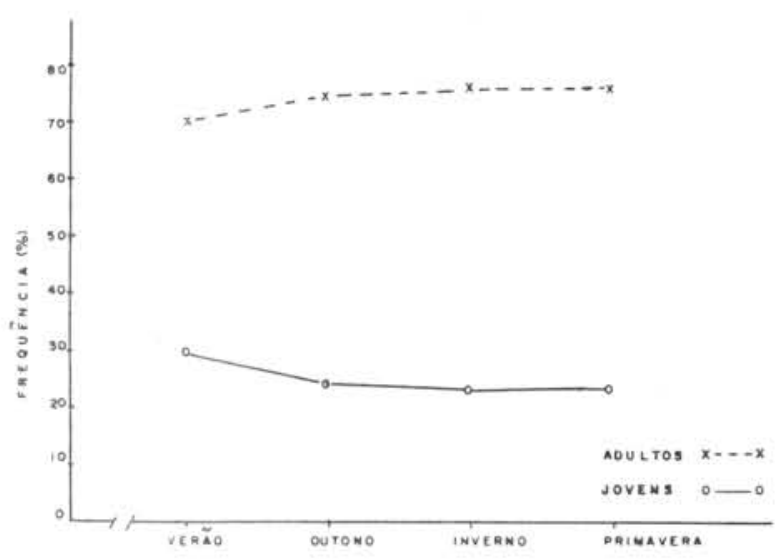

Fig. 10 - Distribuição de freqüência de indivíduos imaturos e maturos de $U$. canosai, por estação do ano.

Fig. 11 - Distribuição de freqüência relativa dos quatro estádios de maturidade, de $U$. canosai, para sexos grupados, por estação do ano.

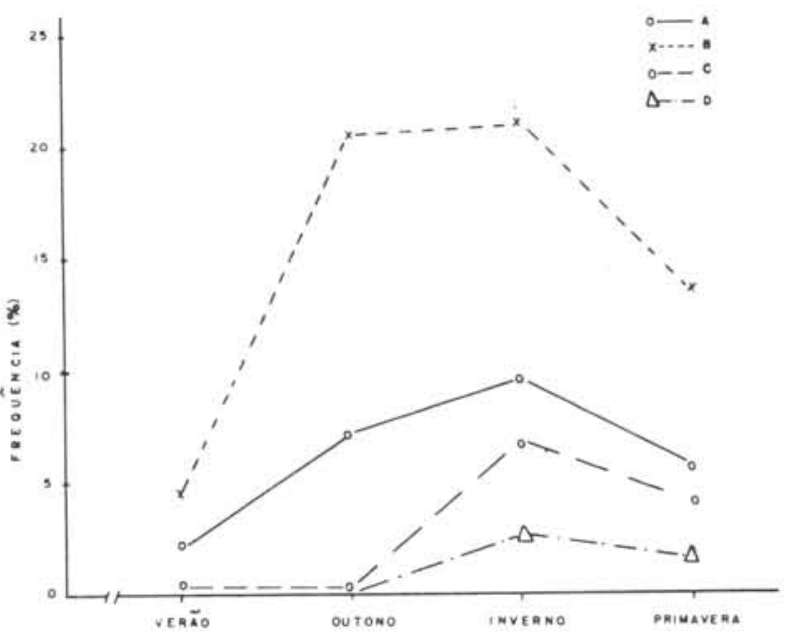


Uma vez determinada a época de desova, foram obtidas as distribuições de freqüência de indivỉduos com gônadas maduras (estädio C) e com gônadas esvaziadas (estádio D), para sexos grupados durante a referida época de desova, em subāreas de 2 em $2^{\circ}$ de latitude. De acordo com o número de ocorrência de indivỉduos em cada estādio, estabeleceu-se níveis de frequência, os quais, representados por símbolos, foram lançados em mapa; a posição dos símbolos dentro de cada subārea considerada não representa a localização geogräfica da ocorrência, mas apenas o nível verificado dentro de cada subārea (Fig. 12).

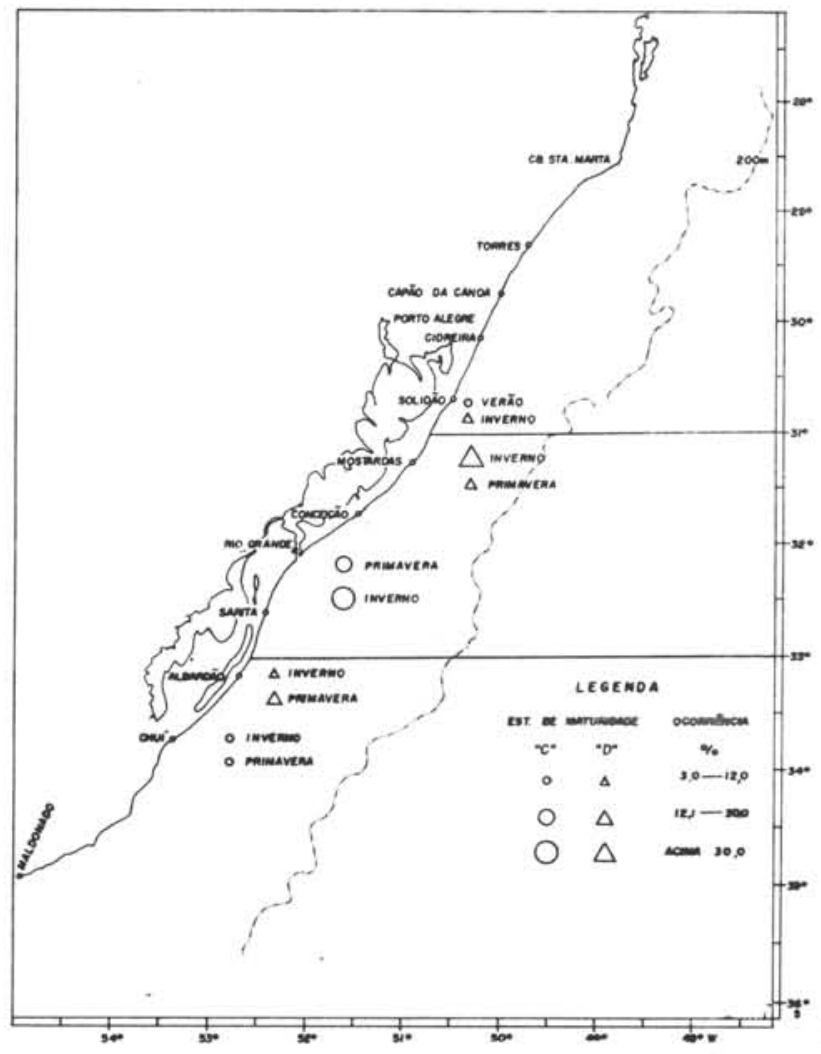

Fig. 12 - Distribuição espacial de freqüência de indivíduos com gônadas maduras (estādio c) e com gônadas esvaziadas (estädio D) de $U$. canosai, durante a ëpoca de desova.

o tipo de desova da espécie fui determinado através da análise das distribuições de freqüência (\%) do diâmetro dos óvulos. Os resultados obtidos para cada par de gônadas foram lançados em gráficos para uma análise individual da distribuição dos diâmetros. As 34 distribuições obtidas foram, a seguir, grupadas segundo a posição da última moda, representativa do grupo de óvulos mais desenvolvidos, procedimento utilizado por Clark (1934), Howard \& Landa (1958) e Vazzoler (1963a; 1969) (Fig. 13). Este gráfico mostra também que os óvulos que se desenvolvem, para serem eliminados na estação de desova seguinte, são os que se diferenciam em 2 lotes (2 modas) a partir de 208 micrômetros de diâmetro. 

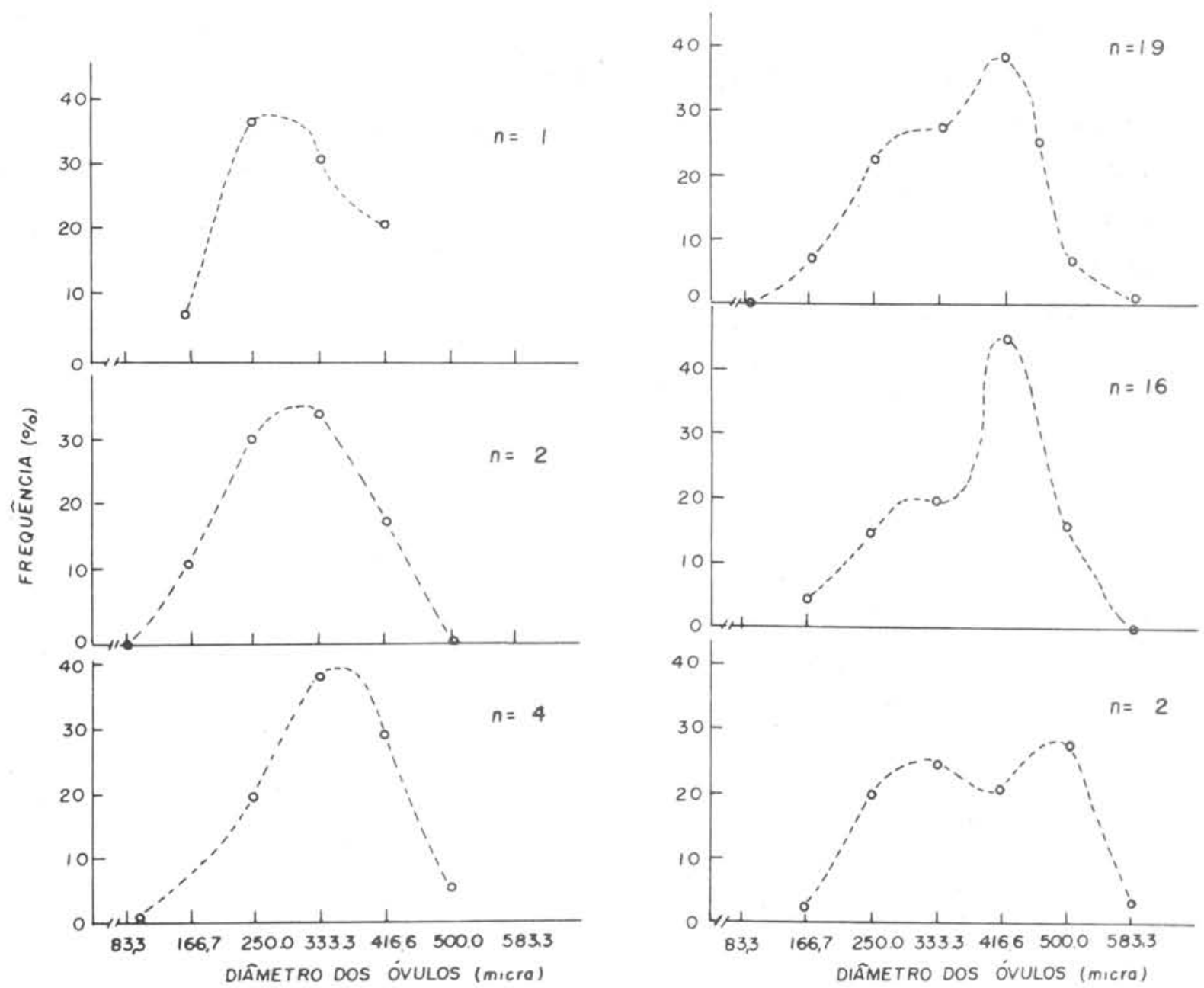

Fig. 13 - Curvas representativas das distribuições de freqüência do diâmetro dos óvulos de gônadas de $U$. canosai, em fase final do estädio B.

Para estimativa da fecundidade, por fêmea, foram considerados apenas os óvulos com diâmetro acima de 208 micrômetros. A Tabela III mostrao número de óvulos (F) que seriam eliminados na estação de desova de 1972, para cada uma das 34 fêmeas examinadas, bem como seu comprimento total ( $\mathrm{L}_{\mathrm{t}} ; \mathrm{mm}$ ), peso total $\left(W_{t} ; g\right)$ e peso das gônadas $\left(W_{g} ; g\right)$.

Foram estudadas as relações entre fecundidade e peso das gônadas $\left(W_{g}\right)$, peso total $\left(W_{t}\right)$ e comprimento total ( $L_{t}$ ) atravēs de anālise de regressão (Fig. 14A, B, C), estando os resultados mostrados nas Tabelas IV A, B).

Foram estudadas as regressões entre peso total $\left(W_{t}\right)$ e comprimento total $\left(\mathrm{L}_{\mathrm{t}}\right)$, por sexo, ajustando-se aos dados a expressão $\mathrm{W}_{t}=\mathrm{a} \mathrm{L}_{\mathrm{t}}^{\mathrm{b}}$, pelo método dos 
TABELA III - Dados relativos às 34 fêmeas utilizadas no estudo da fecundidade

\begin{tabular}{|c|c|c|c|c|c|c|c|c|c|}
\hline $\begin{array}{l}\text { No do } \\
\text { peixe }\end{array}$ & $\mathrm{L}_{\mathrm{t}}(\mathrm{mm})$ & $w_{t}(g)$ & $w_{g}(g)$ & $F$ & $\begin{array}{l}\text { No do } \\
\text { peixe }\end{array}$ & $L_{t}(m m)$ & $w_{t}(g)$ & $W_{g}(g)$ & $F$ \\
\hline 1 & 260 & 335,0 & 17,35 & 216.270 & 18 & 207 & 155,5 & 3,50 & 39.600 \\
\hline 2 & 285 & 380,7 & 13,50 & 204.425 & 19 & 247 & 304,4 & 8,30 & 145.035 \\
\hline 3 & 218 & 147,5 & 20,00 & 293.782 & 20 & 272 & 334,4 & 18,50 & 257.777 \\
\hline 4 & 269 & 269,5 & 2,10 & 27.522 & 21 & 271 & 254,9 & 6,00 & 97.900 \\
\hline 5 & 301 & 399,5 & 7,70 & 138.516 & 22 & 280 & 306,1 & 8,67 & 179.261 \\
\hline 6 & 278 & 346,0 & 15,90 & 259.627 & 23 & 248 & 214,5 & 4,62 & 90.792 \\
\hline 7 & 280 & 345,9 & 16,50 & 283.000 & 24 & 285 & 316,3 & 14,80 & 246.837 \\
\hline 8 & 282 & 345,9 & 15,40 & 224.665 & 25 & 285 & 309,7 & 5,10 & 78.200 \\
\hline 9 & 248 & 367,0 & 13,50 & 273.227 & 26 & 288 & 334,6 & 16,40 & 316.705 \\
\hline 10 & 271 & 277,2 & 6,20 & 128.977 & 27 & 261 & 258,6 & 7,30 & 97.010 \\
\hline 11 & 258 & 258,0 & 11,10 & 206.460 & 28 & 258 & 239,5 & 8,60 & 134.044 \\
\hline 12 & 278 & 345,5 & 16,10 & 312.340 & 29 & 284 & 355,6 & 20,70 & 287.550 \\
\hline 13 & 195 & 113,9 & 1,80 & 38.448 & 30 & 290 & 320,0 & 11,30 & 193.411 \\
\hline 14 & 267 & 329,2 & 17,90 & 298.275 & 31 & 286 & 326,0 & 17,59 & 294.860 \\
\hline 15 & $27 y$ & 310,5 & 9,40 & 202.615 & 32 & 214 & 129,9 & 2,50 & 52.580 \\
\hline 16 & 273 & 239,5 & 15,20 & 217.700 & 33 & 219 & 140,9 & 2,40 & 65.095 \\
\hline 17 & 298 & 398,3 & 6,50 & 195.228 & 34 & 294 & 385,0 & 11,20 & 145.290 \\
\hline
\end{tabular}
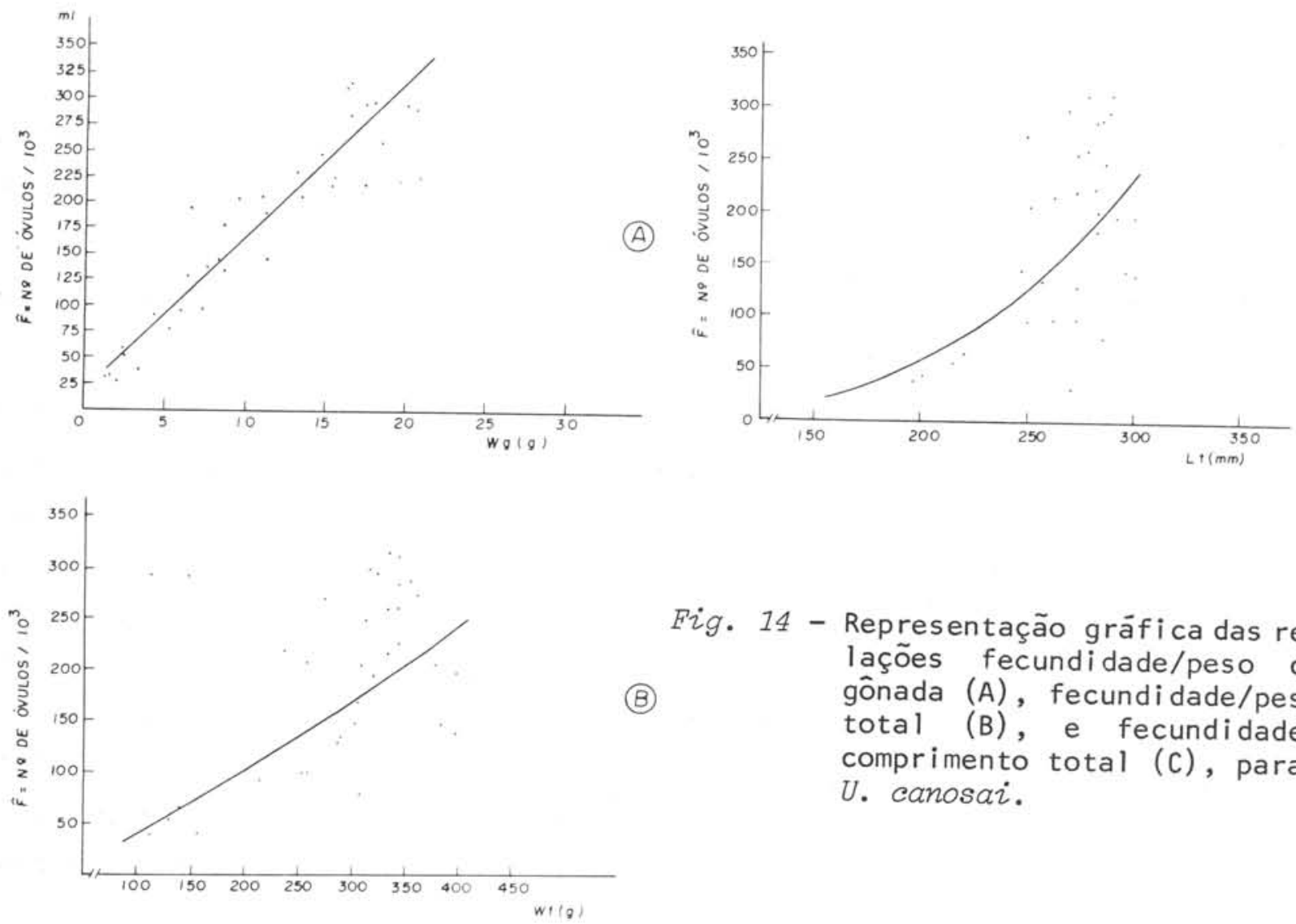

Fig. 14 - Representação gräfica das relações fecundidade/peso da gônada (A), fecundidade/peso total (B), e fecundidade/ comprimento total (C), para $U$. canosai. 
TABELA IV - Parâmetros das regressões:
A) fecundidade $(5)$ e peso das gônadas $\left(W_{g}\right)$;
B) logarítmo da fecundidade ( $\log F$ ) e logarítmo do peso total (log $\left.W_{t}\right)$, e logarítmo da fecundidade $(\log F)$ e logarítmo do compri- mento total $\left(\log L_{t}\right)$

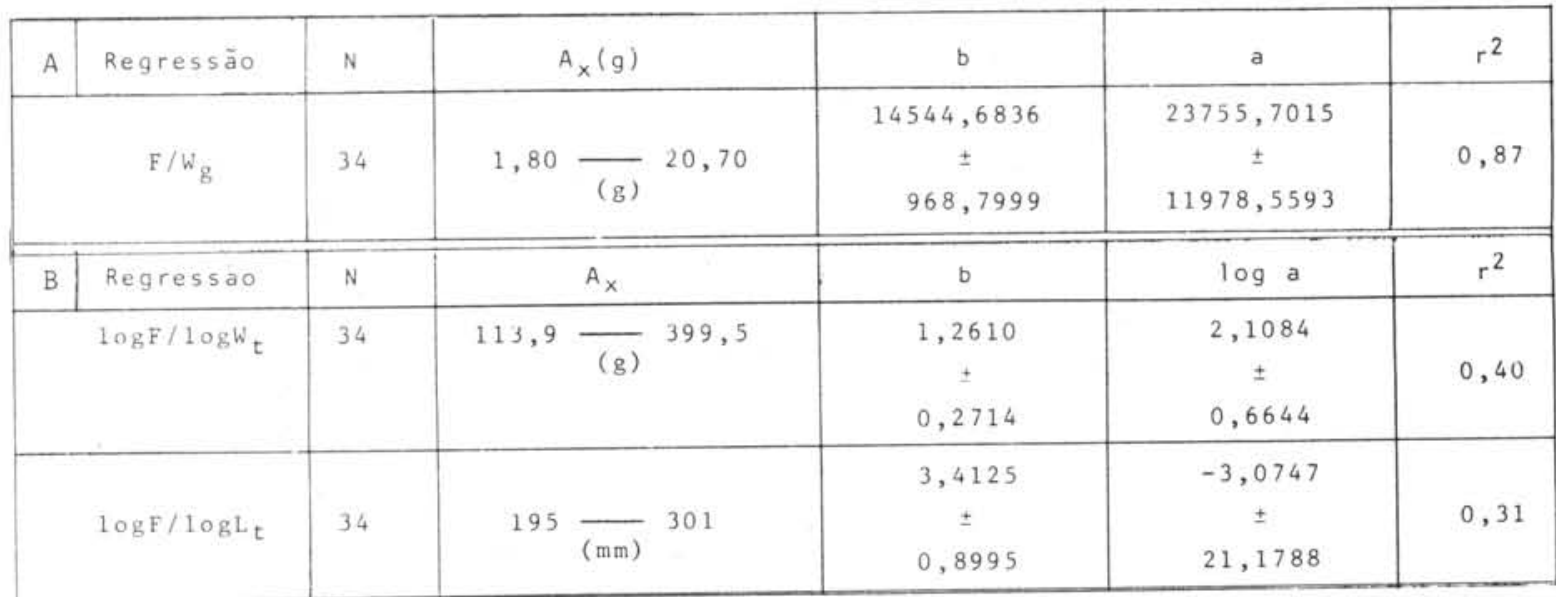

$N$ = nümero de exemplares

$A_{X}=$ amplitude da variável $\times$ (abcissa)

$b=$ valor do coeficiente de regressāo \pm seu desvio padräo

$a=$ valor da constante de regressão \pm seu desvio padräo

$r^{2}=$ coeficiente de determinação

$\log a=$ valor do logarítmo da constante de regressảo \pm seu desvio padrão

mínimos quadrados (após transformação logarítmica). Foram considerados dados sobre esses dois parâmetros relativos a 488 machos e 622 fêmeas; os resultados obtidos no cálculo das regressões constam da Tabela V A. A Figura 15A mostra as curvas que representam essa relação, para cada sexo. Os resultados foram testados através do teste "t" (Tab. V B).

A partir dos dados sobre número de anéis e comprimento total, foram calculados, por estação do ano e para sexos grupados, os comprimentos médios $\left(\overline{\mathrm{L}}_{t}\right)$ por grupo de nümero de anel. Os resultados foram lançados em gráfico para obtenção de indicações sobre a época de formação dos anéis dos otólitos (Fig. 16). Foram aqui considerados os resultados obtidos até o grupo de 10 anéis, por serem os que apresentaram número representativo de indivíduos. A periodicidade da formação de anéis foi testada segundo o método de FordWalford (Beverton \& Holt, 1957). Foram calculadas as curvas de crescimento para fêmeas e para machos, para todo o período considerado, ajustando-se aos dados de comprimento total médio $\left(L_{t}\right)$ e número de anéis ( $I$ ), a expressão de von Bertalanffy $-L_{t}=L_{\infty}\left[1-e^{-k\left(t-t_{0}\right)}\right]$ (Beverton \& Holt, op. cit.). Ape- 
sar dos valores do teste " $t$ ", aplicado aos resultados das regressões entre $\mathrm{L}_{t+1} / \mathrm{L}_{t}$ (Tab. VI A, B), não indicarem diferença significativa entre os sexos, do ponto de vista biológico julgou-se de interesse manter os resultados separados.

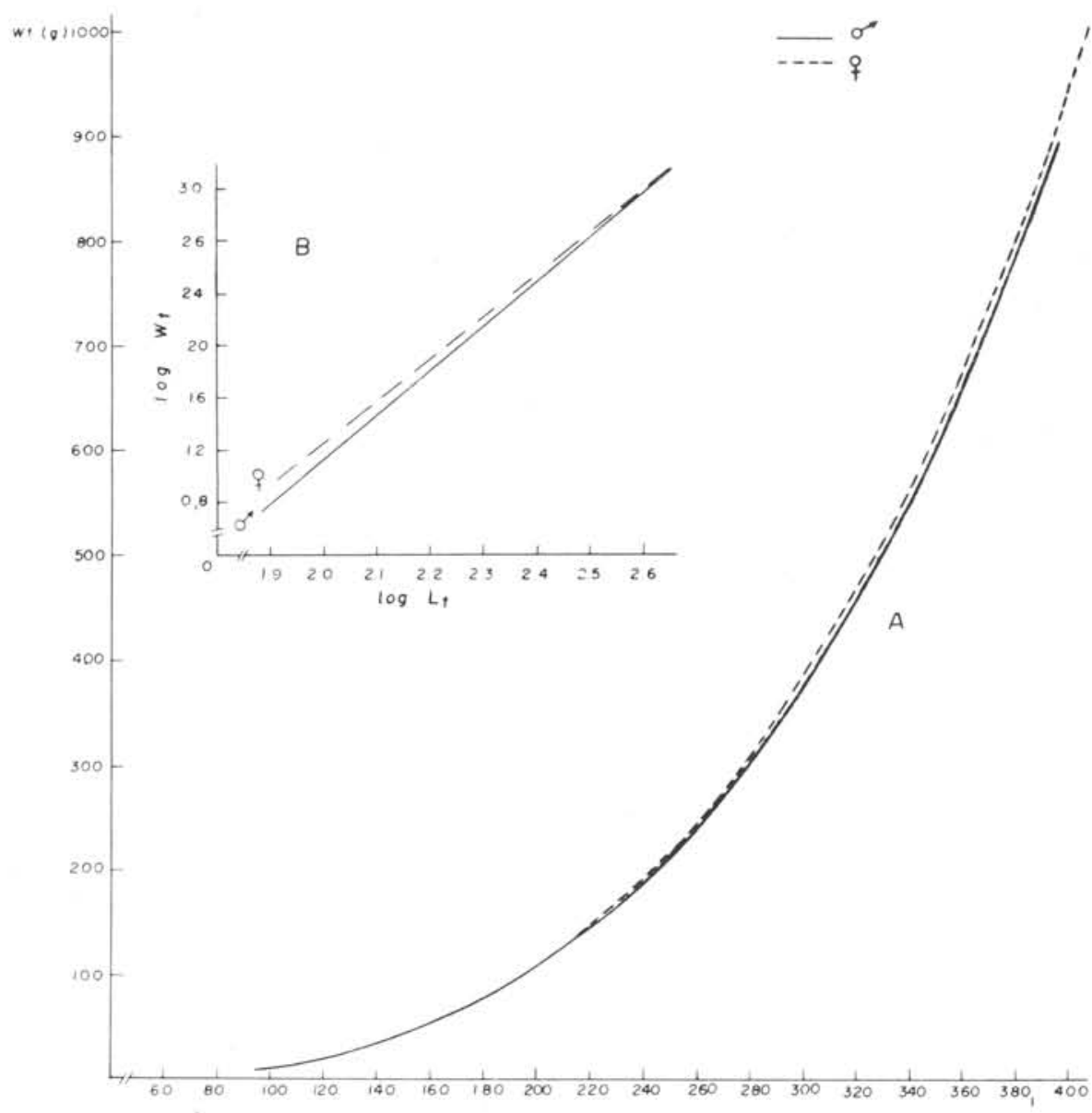

Fig. 15 - A - Representação gräfica da relação entre peso total/comprimento total para machos e fêmeas de $U$. canosai, durante o período estudado.

B - Representação gräfica da relação entre logarítmo do peso total e logarítmo do comprimento total, para machos e fêmeas de $U$. canosai, durante o período estudado.

A Figura 17 A mostra as curvas de crescimento em comprimento, por sexo, 
TABELA V - A) Parâmetros das regressões entre logarítmo do peso total ( $\log W_{t}$ ) e logarítmo do comprimento total ( $\log \mathrm{L}_{t}$ ), por sexo;

B) Resultado do teste " $t$ " aplicado às regressões da Tabela anterior (Tab. V A)

\begin{tabular}{|c|c|c|c|c|c|c|c|}
\hline A & Sexo & $\mathrm{N}$ & & $\times \quad(\mathrm{mm})$ & b & $\log a$ & $r^{2}$ \\
\hline & Fêmeas & 622 & & -407 & $\begin{array}{c}3,0449 \\
\pm \\
0,0135\end{array}$ & $\begin{array}{c}-4,9588 \\
\pm \\
0,0317\end{array}$ & 0,98 \\
\hline & Machos & 488 & 100 & - 398 & $\begin{array}{c}3,1015 \\
\pm \\
0,0175\end{array}$ & $\begin{array}{c}-5,0993 \\
\pm \\
0,411\end{array}$ & 0,98 \\
\hline
\end{tabular}

\begin{tabular}{|c|c|c|c|}
\hline \hline$B$ & Teste entre & $n$ & $t(b)$ \\
\hline Fêmeas $\times$ Machos & 1110 & $2,8300^{*}$ \\
\hline
\end{tabular}

$N=$ nümero de exemplares

$A_{x}=$ amplitude da variävel $\times$ (abcissa)

$b=$ valor do coeficiente de regressảo \pm seu desvio padräo

$\log a=$ valor do logarítmo da constante de regressão \pm seu desvio padräo

$r^{2}=$ coeficiente de determinação

$n=$ nümero total de exemplares

$*=$ significativo ao nível de $5 \%$

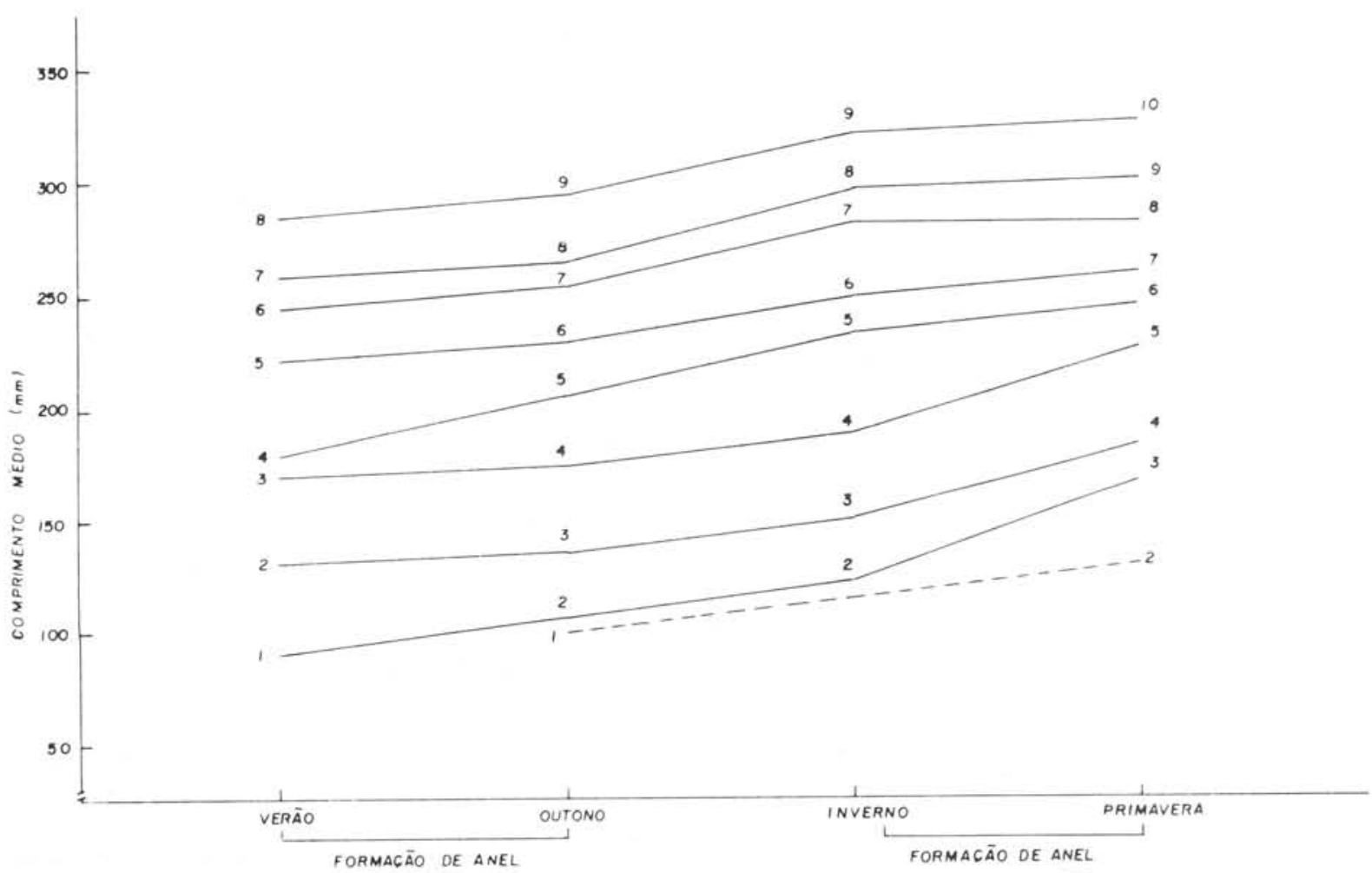

Fig. 16 - Distribuição das médias de comprimento total $\left(\bar{L}_{t}\right)$ de $U$. canosai por grupo de n? de anéis, por estação do ano. 
para a espécie estudada. Os valores obtidos para os parâmetros foram:

\begin{tabular}{|c|c|c|c|c|}
\hline Sexo & $\mathrm{N}$ & $\mathrm{L}_{\infty}(\mathrm{mm})$ & $\mathrm{k}$ & $\mathrm{t}_{\mathrm{o}}$ \\
\hline Fêmeas & 625 & 435,11 & 0,1103 & $-1,6102$ \\
\hline Machos & 490 & 377,11 & 0,1588 & $-0,7334$ \\
\hline
\end{tabular}

$\mathrm{N}=$ numero de exemplares considerados

$\mathrm{L}_{\infty}=$ assíntota do comprimento total

$\mathrm{k}=$ taxa de crescimento

$t_{0}=$ idade inicial (número de anéis)

Com os dados sobre peso total $\left(W_{t}\right)$ e número de anéis (I), por sexo, obteve-se o valor do peso total médio $\left(\bar{W}_{t}\right)$ por grupo de anel. A partir das equações das regressões $W_{t} / L_{t}$, e dos valores obtidos para $L_{\infty}$, estimou-se os valores de $W_{\infty}$ para cada sexo. As equações de crescimento em peso foram obtidas utilizando-se esses valores de Wo e os obtidos no cálculo das curvas de crescimento em comprimento para $\mathrm{k}$ e $\mathrm{t}_{\mathrm{o}}$, por sexo, admitindo-se como verdadeira a lei do cubo (Beverton \& Holt, 1957) (Fig. 17B).

Para análise da distribuição da população dentro da área estudada, em termos de número de indivíduos/hora, por estação do ano, foram traçadas isolinhas de densidade relativa (Figs 18-19). Para o traçado dessas isolinhas foram lançados em mapas os valores relativos a número de indivíduos capturados por hora (PUE), nas respectivas estações oceanográficas onde verificou-se ocorrência da espécie, considerando-se coletas com otter-traw1 (От) e "beam-traw1" (ВT). A seguir, os pontos representativos das estações foram ligados por radiais das quais mediu-se o comprimento (mm), ou seja, a distância entre as duas estações consideradas. Em computador 01ivetti-Programma 101, calculou-se as distâncias entre a estação de menor densidade es pontos correspondentes às densidades prë-estabelecidas de 5, 15, 50, 100, 250, 500, 1000,1500 e 2500 ind/h, dentro dos limites de variação da densidade das duas estações consideradas; tais distâncias foram lançadas no mapa. Os pontos representativos de igual densidade foram adequadamente unidos, obtendo-se assim as isolinhas de densidade relativa. 
TABELA VI - A) Parâmetros das regressões entre $L_{t}+{ }_{1} e L_{t}$, por sexo;

B) Resutado do teste " $t$ " aplicado as regressões da tabela anterior (Tab. VI A)

\begin{tabular}{|c|c|c|c|c|c|}
\hline A Sexo & N & $A_{X}(\mathrm{~mm})$ & $b$ & $a$ & $r^{2}$ \\
\hline \multirow{2}{*}{ Fêmeas } & 17 & 106,75 & 0,8969 & 44,8601 & \\
& & - & \pm & \pm & 0,99 \\
& & 381,00 & 0,0079 & 3,0956 & \\
\hline & 15 & - & 0,8508 & 56,2655 & \pm \\
& & 357,50 & 0,0121 & 4,2373 & 0,97 \\
\hline
\end{tabular}

\begin{tabular}{|c|c|c|c|c|}
\hline \hline$B$ & Teste entre & $n$ & $t(b)$ & $t(a)$ \\
\hline Fêmeas x Machos & 32 & $-1,0945$ & 0,4071 \\
\hline
\end{tabular}

$N=$ nümero de grupos de anëis

$A_{X}=$ amplitude da variävel x (abcissa)

$b=$ valor do coeficiente de regressão \pm seu desvio padrão

$a=$ valor da constante de regressäo \pm seu desvio padräo

$r^{2}=$ coeficiente de determinação

$n=$ nümero total de grupos de anéis

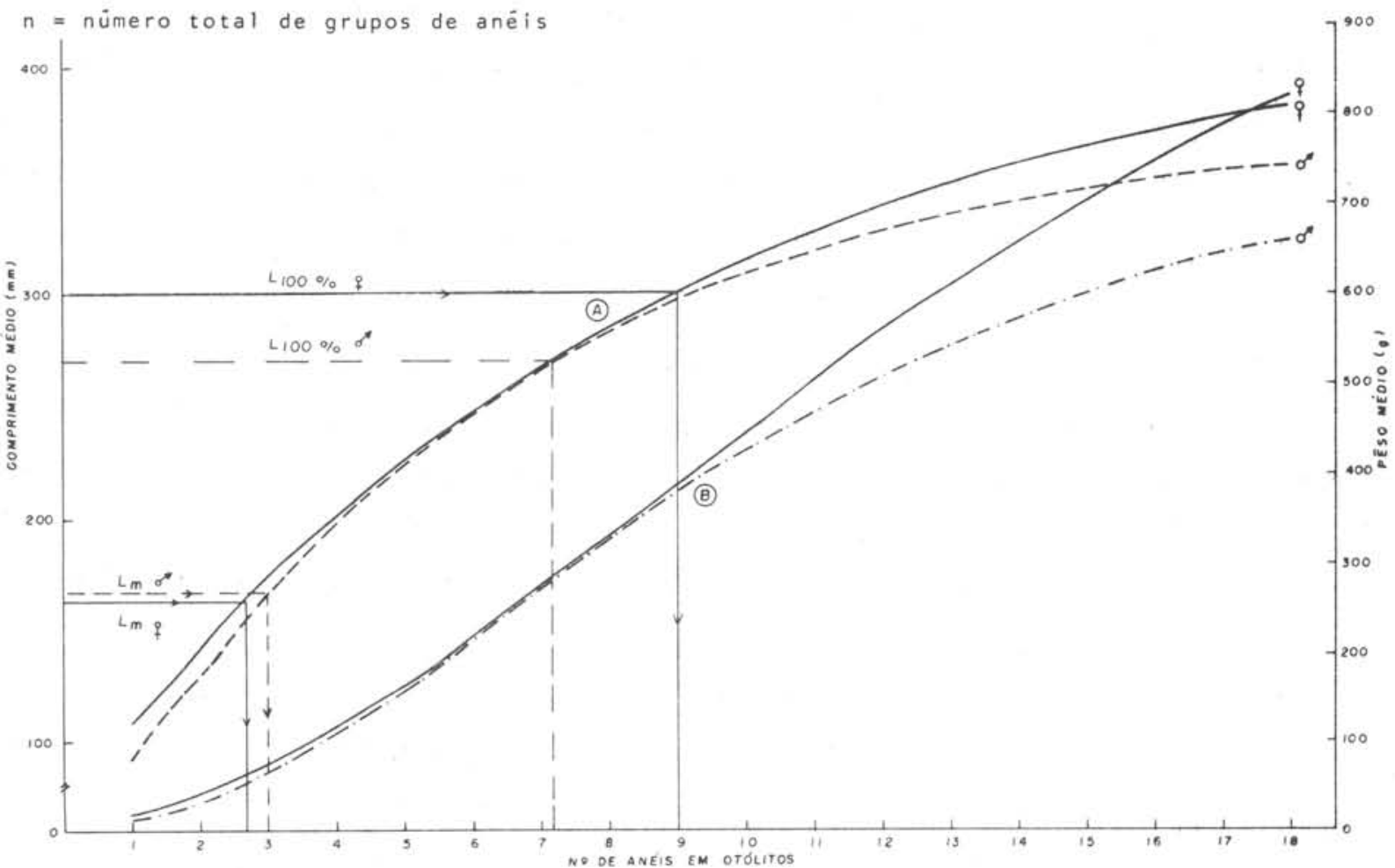

Fig. 17 - A - Curvas de crescimento em comprimento de fêmeas e machos de U. canosai, com indicação dos comprimentos médios de início ( $\left.\bar{L}_{m}\right)$ e conclusão $\left(\mathrm{L}_{100 \%}\right)$ do processo de maturação sexual para o período es tudado.

$B$ - Curvas de crescimento em peso de fêmeas e machos de $U$. canosai, para o período estudado. 


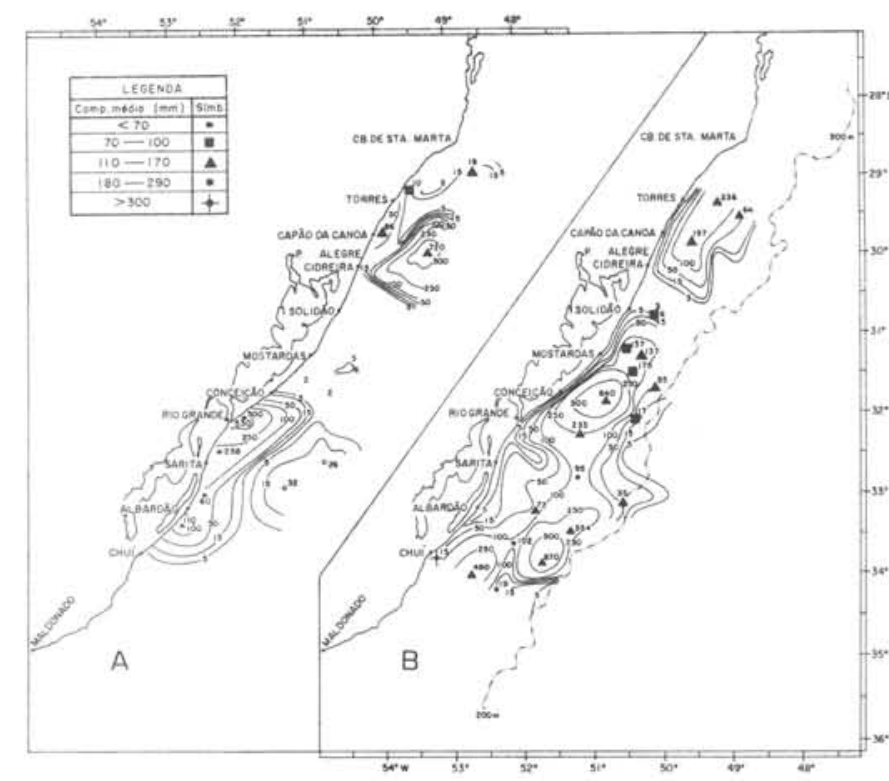

Fig. 18 - Isolinhas de abundância relativa ( $n$ ? de ind./h) de $U$. canosai, no verão (A) e outono (B), com indicação da distribuição espacial das diferentes fases de desenvolvimento.

Para análise da variação espacial da composição da espécie quanto às diferentes fases de desenvolvimento nas quatro estações do ano, calculou-se o comprimento médio dos indivíduos que ocorreram em cada estação oceanogrä́ica, em cada Cruzeiro; os valores de comprimento médio obtidos foram grupados em cinco categorias, correspondentes às seguintes fases de desenvolvimento:

$$
\begin{aligned}
& \text { "jovens menores" } \quad \text { abaixo de } 70 \mathrm{~mm} \\
& \text { "jovens pequenos" } \quad \text { de } 70 \longleftarrow 100 \mathrm{~mm} \\
& \text { "jovens grandes" }- \text { de } 100 \longleftarrow 170 \mathrm{~mm} \\
& \text { "adultos pequenos" - de } 180 \longleftarrow 290 \mathrm{~mm} \\
& \text { "adultos grandes" - acima de } 300 \mathrm{~mm}
\end{aligned}
$$

Os símbolos representativos dessas categorias foram lançados nos mapas de distribuição das isolinhas de densidade relativa, no local de cada estação, como mostrado nas Figuras 18 e 19 .

Para uma análise do comportamento da espécie em relação à profundidade e distribuição de propriedades hidrológicas como temperatura, salinidade eteor de oxigênio dissolvido, os dados sobre freqüência (\%) de densidade relativa, quanto a número de indivíduos/hora (PUE) foram lançados em gráfico contra os valores de profundidade e de cada uma das propriedades acima citadas (Figs 20-23) . 
Fig. 19 - Isolinhas de abundância
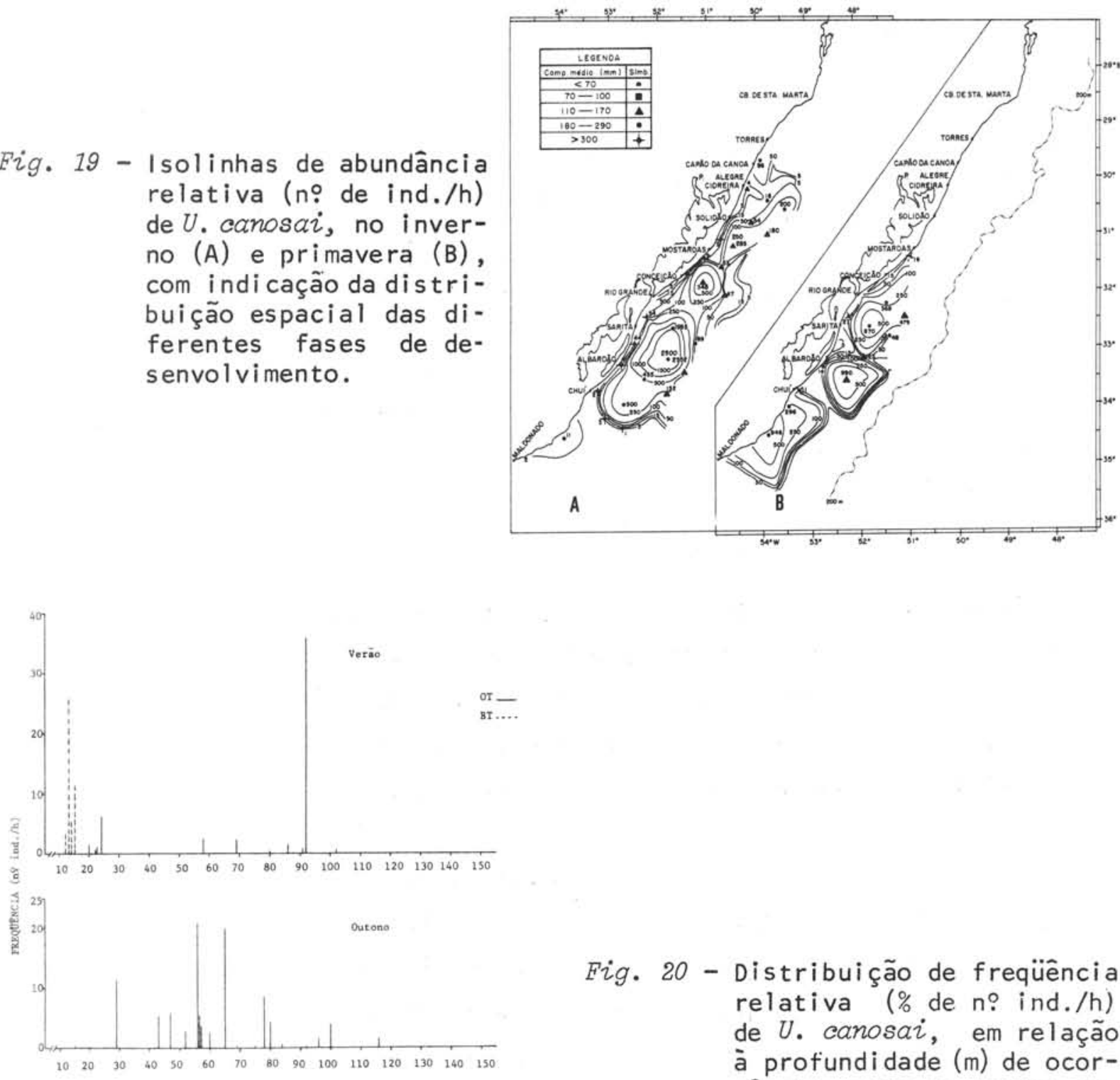

Fig. 20 - Distribuição de freqüência relativa (\% de n? ind./h) de $U$. canosai, em relação à profundidade $(\mathrm{m})$ de ocorrência, para as quatro es-

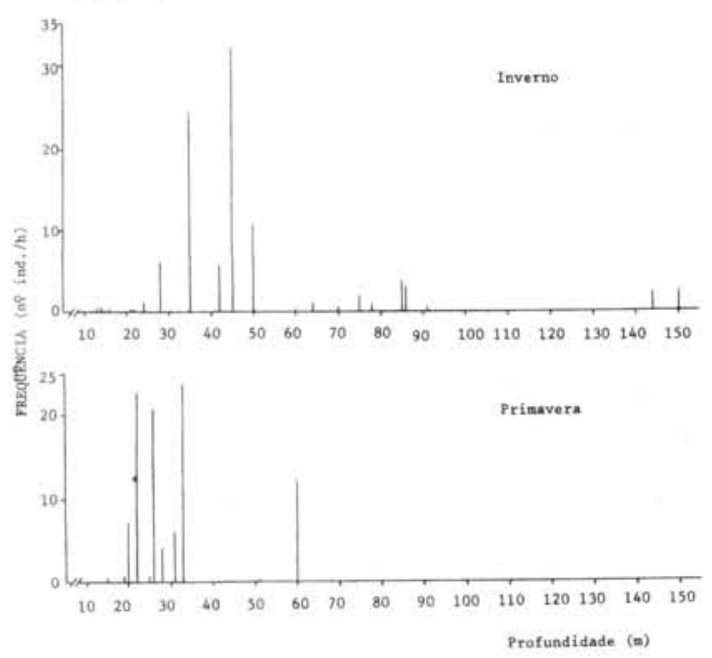
tações do ano. 

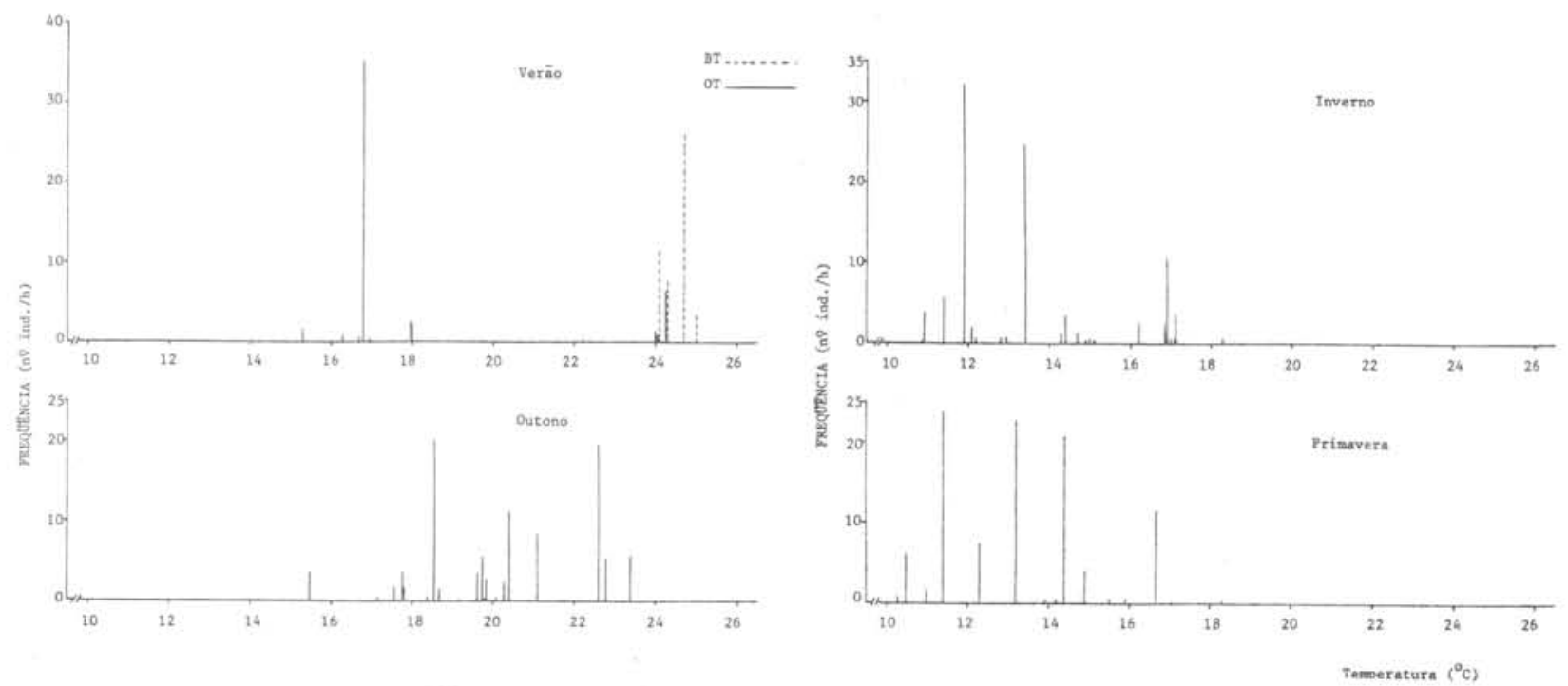

Fig. 21 - Distribuição da freqüência relativa (\% de $n$ ? ind./h) de U. cçnosai, em relação à variação de temperatura, para as quatro estações do ano.

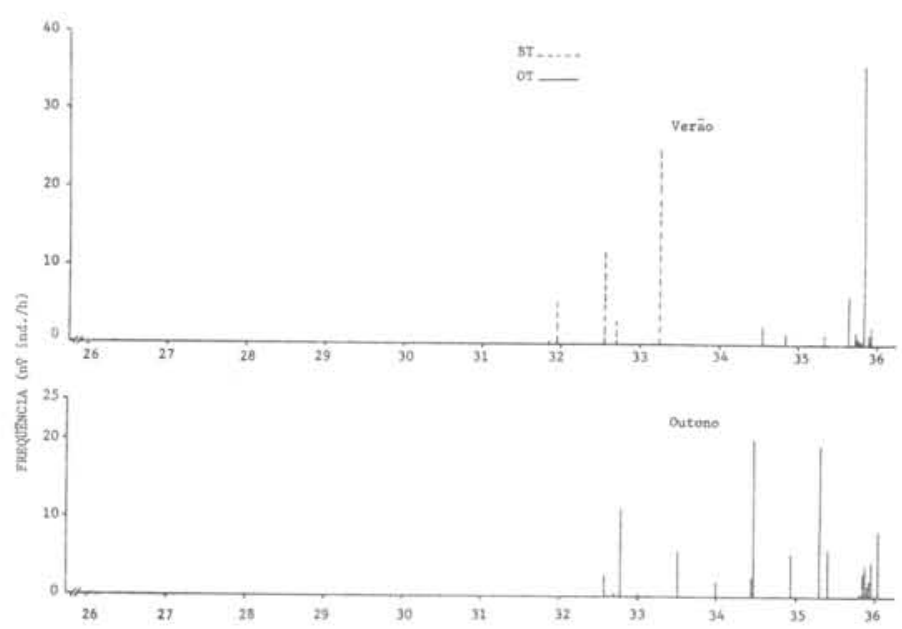

Fig. 22 - Distribuição da freqüência relativa $(\%$ de n? ind./h) de $L^{\prime}$. canosai, em relação à variação de salinida-

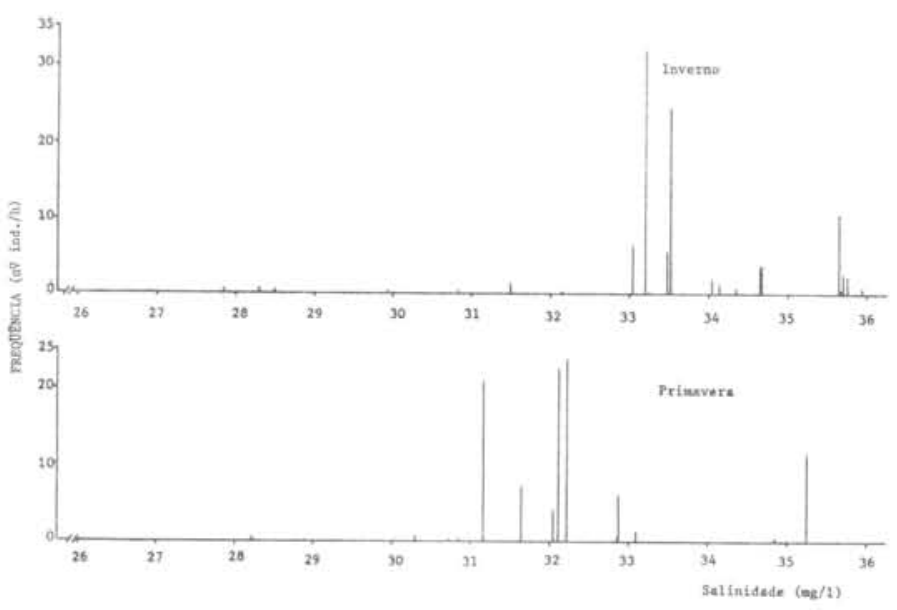
de $(5 \% 0)$, para as quatro estações do ano. 
Todos os resultados sobre distribuição das diferentes fases de desenvolvimento dos indivíduos, localização dos principais nücleos e isotermas nas proximidades do fundo foram utilizados simultaneamente para uma análise global das variações sazonais no comportamento da espécie (Fig. 24).

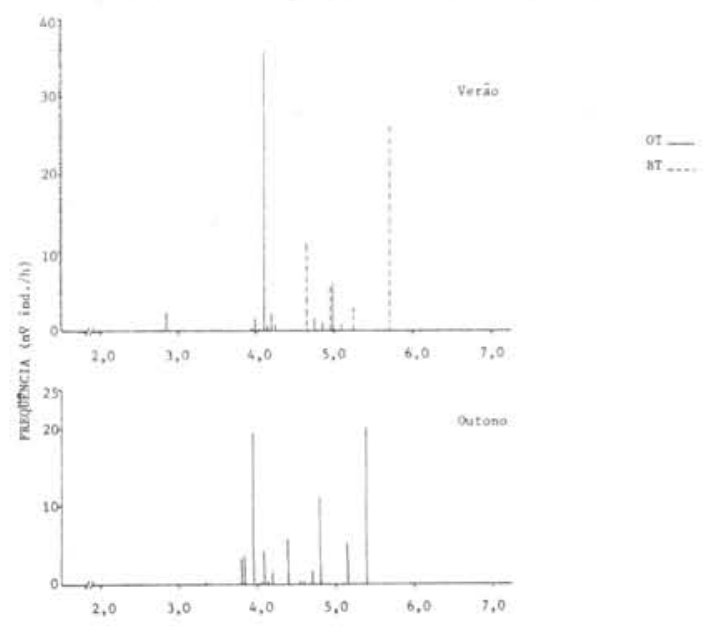

Fig. 23 - Distribuição da freqüência relativa (\% de $n$ ? ind./h) de $U$. canosai, em relação à variação do teor de oxigênio dissolvido (ml/1) para as quatro estações do ano.

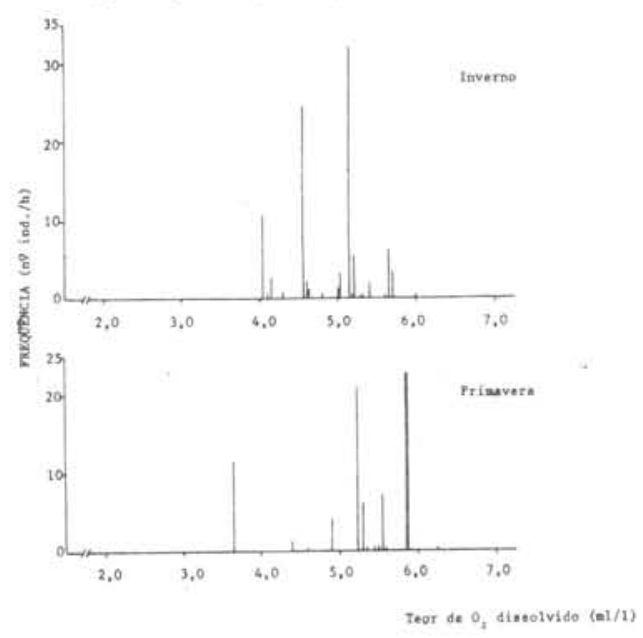

Fig. 24 - Representação esquemätica de distribuição espacial das diferentes fases de desenvolvimento em relação às isotermas nas proximidades do fundo, durante o período estudado.

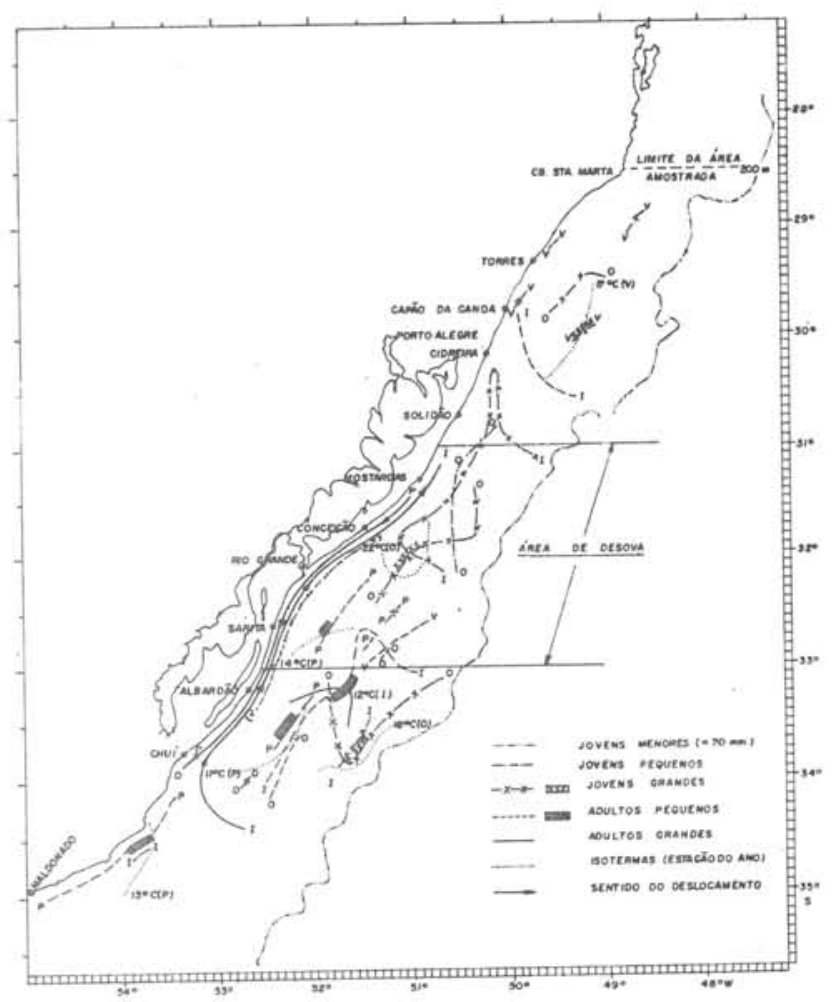




\section{RESULTADOS}

A Figura 5 indica que durante o período estudado ocorreram exemplares numa amplitude de comprimento de 60 a $407 \mathrm{~mm}$. Durante as estações do ano, houve variação na amplitude de comprimentos; no verão, entre 60 e $298 \mathrm{~mm}$; no outono, entre 75 e $318 \mathrm{~mm}$; no inverno, entre 98 e $407 \mathrm{~mm} \mathrm{e}$, na primavera, entre 104 e $384 \mathrm{~mm}$. Os resultados mostram ainda que, durante o verão e outono, há entrada para a população de indivíduos entre 60 e $120 \mathrm{~mm}$ (jovens) fornecendo indicações de ser essa a época de recrutamento. 0 fluxo maior de entrada ocorreria principalmente no verão, pois as freqüências dos grupos de indivíduos com 1 e 2 anéis (72\%) destacam-se na distribuição de freqüência dos grupos de nümero de anêis (Fig. 6).

Durante o inverno e primavera, observa-se que a população è constituída principalmente de indivỉduos entre 170 e $300 \mathrm{~mm}(65,3 \%$ e 57\%, respectivamente, o que sugere um predomínio de indivíduos numa fase de desenvolvimento mais avançada (Fig. 5).

Verifica-se uma correspondência entre as distribuições totais de freqüência de classes de comprimento e de grupos de nümero de anéis, com predomínio de indivíduos que apresentam de $110-250 \mathrm{~mm}$ correspondendo aos grupos de 2 a 6 anëis (Figs 7A, B).

Quanto ao "sex-ratio" na população, a anālise da Figura 8 indica que durante o outono e inverno hā acentuada predominância de fêmeas, sendo essa diferença significativa (Tab. II); durante a primavera e verão, a frequêencia de ambos os sexos è quase a mesma.

A Figura 9 mostra o comprimento total médio (mm) no qual $50 \%$ dos indivíduos machos, e $50 \%$ de fêmeas da população iniciama primeira maturação sexual $\left(\overline{\mathrm{L}}_{\mathrm{m}}\right)$ e o comprimento total ( $\left.\mathrm{mm}\right)$, em que todos os indivíduos (machos e fêmeas) estão adu1tos ( $\left.\mathrm{L}_{100 \%}\right)$.

Numa comparação entre os valores obtidos para $\overline{\mathrm{L}}_{\mathrm{m}}$ e $\mathrm{L}_{100 \%}$ com os obtidos no estudo sobre crescimento (Fig. 17A) observa-se que o processo de maturação sexual inicia-se dentro do 2 ? ano de vida tanto para os machos como para 
as fêmeas. Os resultados obtidos foram os seguintes:

\begin{tabular}{|c|c|c|c|c|}
\hline Sexo & $\overline{\mathrm{L}}_{\mathrm{m}}(\mathrm{mm})$ & ano de vida & $\mathrm{L}_{100 \%}(\mathrm{~mm})$ & ano de vida \\
\hline Fêmeas & 166,5 & $2 \%$ ano & 300 & $4 \%$ ano \\
\hline Machos & 177,0 & $2 \%$ ano & 270 & $5 \%$ ano \\
\hline
\end{tabular}

A entrada de indivỉduos jovens na população (Fig. 10) se dá, principalmente, no verão, coincidindo com o sugerido pelas distribuições de freqüência das classes de comprimento e de grupos de anéis (Figs 5-6). Há indicações da entrada de jovens em menor grau no outono, o que poderia ser explicado pela desova parcelada que a espécie apresenta.

A anālise das distribuições de freqüência dos estádios de maturidade, para sexos grupados por estação do ano, (Fig. 11) indica que a maior freqüência de indivíduos com gônadas esvaziadas (estádio D) não ocorre logo em seguida à maior freqüência de indivíduos maduros (estádio $\mathrm{C}$ ), assim como a freqüência máxima de indivíduos em maturação (estādio B) não è seguida de um aumento na freqüência de indivíduos maduros (estádio C). Durante o inverno, ocorre a maior frequêencia de indivíduos maduros (estádio C) que se prolonga atē a primavera; tais resultados mostram que a desova ocorre no período inverno+primavera e verão. 0 pico de indivĩduos em maturação (estádio B), no outonoinverno, representa o conjunto dos indivíduos $B_{1}$ e $B_{2}$ representativo de desova parcelada: a gônada madura (estádio C), elimina um lote de óvulos (aqueles que atingiram desenvolvimento total) e retorna ao estádio $B\left(B_{2}\right)$, ocorrendo maturação do outro lote de ov́ulos $\left(\mathrm{C}_{2}\right)$ que serā eliminado, passando a gônada para o estádio D, segundo o esquema abaixo:

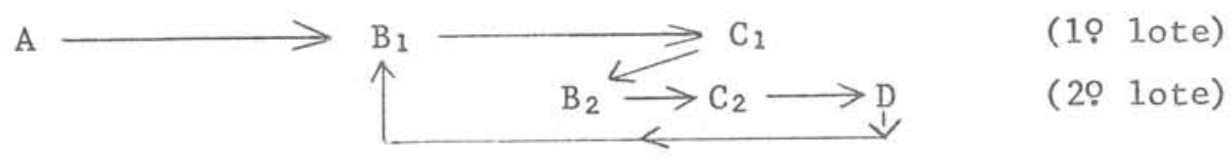

A Figura 12 mostra que a maior freqüência de indỉviduos com gônadas maduras ocorre no periodo inverno-primavera, na região entre $31-33^{\circ} \mathrm{S}$, sendo que indivíduos com gônadas esvaziadas ocorrem ao longo de toda a área entre 31$35^{\circ} \mathrm{S}$, com maior intensidade no inverno entre $31-33^{\circ} \mathrm{S}$, e na primavera entre 
$33-35^{\circ} \mathrm{S}$. Esta distribuição espacial indica que a ärea entre $31-33^{\circ} \mathrm{S}$ constitui o local de desova mais intensa da espécie.

As distribuições de freqüência de diâmetro dos óvulos (Fig. 13) reforçam a indicação anterior de que a desova é parcelada. As duas modas das distribuições, que se desenvolvem a partir de um dado momento, dentro do processo de maturação, mostram que existem nas gônadas dois lotes de óvulos, em duas fases de desenvolvimento; indica ainda que os óvulos com diâmetro a partir de 208 micrômetros desenvolver-se-ão para serem eliminados na estação de desova seguinte.

A fecundidade das 34 fêmeas estudadas variou de 27.522 a 316.705 óvulos; seus comprimentos totais variaram entre 195 e $301 \mathrm{~mm}$; seus pesos totais, entre 113,9 e $399,5 \mathrm{~g}$, e os pesos de suas gônadas variaram de 1,8 a $20,7 \mathrm{~g}$.

A reta de regressão representativa da relação fecundidade e peso total da gônada está representada na Figura 14A, sendo a expressão da mesma:

$$
\hat{\mathrm{F}}=23.755,70+14.544,68 \mathrm{w}_{\mathrm{g}}
$$

onde $\hat{\mathrm{F}}=$ número estimado de óvulos que serão eliminados, por fêmea, numa estação de desova; $\mathrm{W}_{\mathrm{g}}=$ peso das gônadas em gramas .

A relação entre fecundidade e peso total (exponencial) está mostrada na Tigura 14B, sendo a expressão da mesma a seguinte:

$$
\widehat{\mathrm{F}}=128,2 \mathrm{w}_{\mathrm{t}}{ }^{1,2610}
$$

onde $\widehat{F}=$ numero estimado de óvulos que serão eliminados, por fêmea, na estação de desova; $W_{t}=$ peso total em gramas .

A relação entre fecundidade e comprimento total (exponencial) apresentou baixo grau de correlação $\left(r^{2}=0,31\right)$, sendo mostrada na Figura $14 \mathrm{C}$ e representada pela expressão:

$$
\hat{\mathrm{F}}=0,0008 \mathrm{~L}_{\mathrm{t}}^{3,4125} \text {, }
$$

onde $\widehat{F}$ = número estimado de óvulos que serão eliminados, por fêmea, na estação de desova; $\mathrm{L}_{\mathrm{t}}=$ comprimento total em milímetros.

A relação peso total/comprimento total (Fig. 15A) determinada para ma- 
chos e para fêmeas é representada pelas equações exponenciais que se seguem:

$$
\begin{aligned}
& \text { Fêmeas: } \mathrm{W}_{\mathrm{t}}=0,000011 \mathrm{~L}_{\mathrm{t}}^{3,0449} \\
& \text { Machos: } \mathrm{W}_{\mathrm{t}}=0,000008 \mathrm{~L}_{\mathrm{t}}^{3,1015}
\end{aligned}
$$

Os resultados do teste " $t$ " aplicado às equações acima (Tab. V B) mostram ocorrer diferença significativa entre sexos (Fig. 15B).

Os anéis dos otólitos formam-se em duas épocas do ano (Fig. 12): um entre o verão e outono, e outro entre o inverno e primavera.

As curvas de crescimento em comprimento (Fig. 17A) mostram que as fêmeas atingem comprimento máximo teórico $\left(\mathrm{L}_{\infty}\right)$ mais elevado que os machos. A taxa de incremento no crescimento não difere estatisticamente entre os sexos (Tab. VI B), entretanto, como jā dissemos anteriormente, julgamos de interesse mantê-1os separados. As equações que expressamo crescimento em comprimento são:

$$
\begin{aligned}
& \text { Fêmeas: } L_{t}=435,11\left[1-e^{-0,1103(t+1,6102)}\right] \\
& \text { Machos: } L_{t}=377,11\left[1-e^{-0,1588(t+0,7334)}\right]
\end{aligned}
$$

Com relação ao crescimento em peso encontramos para fêmeas $W_{\infty}=1.189,0 \mathrm{~g}$ e para machos $W_{\infty}=774,5 \mathrm{~g}$ (Fig. 17B). As equações representativas do crescimento em peso, por sexo são:

$$
\begin{aligned}
& \text { Fêmeas: } W_{t}=1.189,0\left[1-e^{-0,1103(t+1,6102)}\right]^{3} \\
& \text { Machos: } W_{t}=774,5\left[1-e^{-0,1588(t+0,7334)}\right]^{3}
\end{aligned}
$$

As distribuições espaciais dos principais núcleos de abundância variaram durante o período estudado. No verão pode-se observar uma concentração elevada entre Torres e Cidreira, onde predominam indivíduos "jovens grandes" (110 $170 \mathrm{~mm})$, uma concentração menor, localizada entre Rio Grande e Albardão, de indivíduos "adultos pequenos" (180 tração de indivíduos "jovens menores" (abaixo de $70 \mathrm{~mm}$ ) entre Albardão e Conceição, bem junto à costa (Fig. 18A). No outono, os indivíduos estão dispersos na plataforma onde se formam três núcleos principais de "jovens gran- 
des": um, entre Torres e Cidreira, outro, entre Mostardas e Rio Grande, e um terceiro, de Albardão para o sul até Chuí (Fig. 18B). No inverno, ocorre uma distribuição de nūcleos em profundidades menores, sendo que as ocorrências costeiras constituem-se de indivíduos "adultos grandes" (acima de $300 \mathrm{~mm}$ ). 0 núcleo mais abundante constituído de indivíduos "adultos pequenos", 1ocaliza-se em posição mais afastada da costa, diante de Albardão; na altura de Conceição ocorre um nücleo bastante abundante de indivíduos "jovens grandes". Observa-se ainda que durante esse período foram registradas as maiores capturas por unidade de esforço (PUE), destacando-se a região entre Rio Grande e Chuí (Fig. 19A). Na primavera, hä indicações de que as ocorrências de indivíduos "adultos grandes" ainda permanecem junto à costa. Destacam-se três nūcleos principais: a) entre Rio Grande e Albardão, com predomínio de indivíduos "adultos pequenos"; b) entre Albardão e Chuí, onde predominam os indivíduos "jovens grandes"; c) entre Chuí e Maldonado, altura de Cabo Polônio, onde ocorrem indivíduos "adultos pequenos" (Fig. 19B).

Os resultados da variação de freqüência do número de indivíduos/hora com a profundidade, por estação do ano (Fig. 20) mostram que, no verão, a popu1ação encontra-se mais concentrada em torno de $90 \mathrm{~m}$ e entre $12-15 \mathrm{~m}$ de profundidade, ocorrendo, entretanto, desde 12 até $102 \mathrm{~m}$; no outono, a amplitude de variação foi maior, com ocorrências entre 15 e $116 \mathrm{~m}$, com concentrações maiores em torno de $30 \mathrm{~m}$ e entre 50-80 m; no inverno, houve capturas desde a profundidade de 13 atē $150 \mathrm{~m}$, com maior abundância na faixa dos 30-50 m; e na primavera, as profundidades de ocorrência foram entre 15 e $60 \mathrm{~m}$, com maior abundância na faixa de 20-35 e em torno de $60 \mathrm{~m}$.

As relações entre freqüência de número de indivíduos/hora, com a distribuição de temperatura na camada de āgua próxima ao fundo (Fig. 21), durante os quatro períodos estudados, mostram que no verão a temperatura variou entre 14,5 e $24,9^{\circ} \mathrm{C}$, com maior abundância de indivíduos entre $16-17^{\circ} \mathrm{C}$ e $24-$ $24,9^{\circ} \mathrm{C}$; no outono, a amplitude de variação da temperatura foi menor, abrangendo de $15,5-23,4^{\circ} \mathrm{C}$, sendo que a maior concentração ocorreu entre $18,5-23^{\circ} \mathrm{C}$; no inverno, quando os valores de temperatura foram relativamente baixos, a amplitude de variação foi de $10,4-18,3^{\circ} \mathrm{C}$, com concentrações maiores na faixa de $11,9-13,5^{\circ} \mathrm{C}$; e na primavera, quando as àguas ainda apresentam temperatura baixa, a amplitude abrangeu de $10,3-18,3^{\circ} \mathrm{C}$, com maior abundância na faixa de $11,4-14,4^{\circ} \mathrm{C}$. 
A análise gráfica dos resultados da variação das distribuições de freqüência de número de indivíduos/hora com a salinidade, durante todo o período estudado (Fig. 22), mostra que, no verão, a amplitude de variação foi de $31,8-35,9 \%$, e as maiores concentrações de indivíduos ocorreram entre 35,6$35,9 \%$ e $32,5-33,3 \%$; no outono, a amplitude de variação da salinidade foi de 32 a $36 \%$ com maior abundância na faixa entre $34,4-35,3 \%$ e em torno de $32,7 \%$; no inverno, houve captura em äguas com salinidade baixa, sendo que a amplitude foi de $26,8-36,0 \%$, com maior ocorrência de indivíduos nas faixas de $33-33,6 \%$ e em torno de $35,5 \% \circ$; na primavera, ainda aparecem capturas em águas de baixa salinidade, tendo a amplitude abrangido de 28,2 a $35,2 \%$, com maior concentração na faixa de 31 a $32,3 \%$.

Os resultados da variação da freqüência do número de indivíduos/hora com o teor de oxigênio dissolvido na água da camada de fundo (Fig. 23), mostram que no verão registrou-se o menor teor (abaixo de 3,0 m1/1), com amplitude de variação entre $2,8-5,7 \mathrm{ml} / 1$ sendo que as maiores concentrações de indivíduos ocorreram em torno de 4,0-4,7 ml/1 e 5,7 ml/1; no outono, a amplitude de variação foi de 3,4-5,4 m1/1, com abundância maior em torno de $3,9 \mathrm{ml} / 1$ e de $5,4 \mathrm{ml} / 1$; no inverno, o teor de oxigênio dissolvido na água alcançou os maiores valores e a amplitude de variação foi de 4,0 a 6,2 m1/1, com ocorrência de maior abundância na faixa de 4,6 a 5,2 ml/1, e na primavera, a amplitude foi de 3,7 a $6,3 \mathrm{ml} / 1$ com maior abundância entre 5,2 a 5,9 ml/1 e em torno de $3,7 \mathrm{ml} / 1$.

A anālise da freqüência de ocorrência em fundos arenosos (areia e areia lodosa) e em lodosos (lama e lama arenosa), mostrou que nos quatro Cruzeiros predominaram as ocorrências em fundos arenosos.

\section{DISCUSSÃO}

Segundo Gilbert (1966), Umbrina canosai ocorre no At1ântico Sul-Ocidental, com distribuição pouco ampla, do sul do Brasil à Argentina; os limites dessa ārea não estão bem delimitados, existindo registros seguros para Montevideo, no Uruguai, e Mar de1 Plata, na Argentina. 
Durante este estudo, foram realizadas algumas coletas entre $28^{\circ} 30^{\prime} \mathrm{S}$ e $29^{\circ} \mathrm{S}$, no verão, sendo que em nenhuma ocorreu $U$. canosai; entretanto, em etapa posterior, foram efetuadas coletas na plataforma continental entre $29^{\circ} 21^{\prime} \mathrm{S}$ (Torres) e $23^{\circ} \mathrm{S}$ (Cabo Frio) quando se registrou ocorrência da espécie até $23^{\circ} 20^{\prime} \mathrm{S}$ (Rio de Janeiro). Desse modo, podemos complementar a informação de Gilbert (op. cit.) estendendo a ārea de distribuição da espécie atē a latitude de $23^{\circ} \mathrm{S}$, sendo que nessa região da plataforma, a ocorrência apresenta densidades relativas maiores ao sul de $28^{\circ} \mathrm{S}$ e nas imediações do Rio de Janeiro.

Temperaturas elevadas constituiriam fator limitante à distribuição da espécie, pois os resultados obtidos mostram que $U$. canosai, com exceção de suas fases bem jovens, é uma espécie que exige condições ambientais onde as āguas apresentem temperaturas baixas (inferiores a $16^{\circ} \mathrm{C}$ ); sendo uma espécie característica de āreas temperadas, penetraria, em maior intensidade, na costa sul brasileira nas épocas em que esta é invadida por āguas frias, subantárticas.

Relacionando os resultados obtidos quanto às variações sazonais na distribuição espacial da espécie, esquematizados na Figura 24 , com dados de Miranda et al.(1973) e Magliocca (1973), observa-se que, no verão, a temperatura das āguas próximas ao fundo decresce com a distância da costa, de um valor mäximo de $24^{\circ} \mathrm{C}$ até cerca de $10^{\circ} \mathrm{C}$, sendo que entre Capão da Canoa $\left(29^{\circ} 46^{\prime} \mathrm{S}\right)$ e Cidreira $\left(30^{\circ} 19^{\prime} \mathrm{S}\right)$ ocorre uma ārea com temperaturas entre 18$16^{\circ} \mathrm{C}$, mais próxima à costa (āgua subtropical); è nessa região, a $91 \mathrm{~m}$ de profundidade que se observou a maior concentração de indivíduos, na fase de "jovens grandes" e uma concentração entre Albardão e Conceição de "jovens menores" em profundidades de 12 a $15 \mathrm{~m}$ em āguas com temperaturas em torno de $24^{\circ} \mathrm{C}$, mostrando que as fases iniciais vivem em condições de temperatura distintas das fases mais desenvolvidas. Nessas regiões, as salinidades eram de $35,8^{\circ} / 0 \circ$ e $31,9-33,3^{\circ} / 0$ e o teor de oxigênio dissolvido de 4,1 m1/1 e 4,5-5,7 ml/1, respectivamente. No outono, hā um decrēscimo da temperatura na região costeira, sendo que a diferença máxima de variação ocorre no extremo sul da região (Chuî); de Rio Grande para o norte, hả uma aproximação gradual de àguas de origem tropical, ocasionando aumentos de temperatura e salinidade. Nesse período, observou-se dois nücleos de maior densidade: um, ao norte de Rio 
Grande $\left(32^{\circ} 08^{\prime} \mathrm{S}\right)$; e outro, ao sul, na altura de Albardão ( $\left.33^{\circ} 11^{\prime} \mathrm{S}\right)$; o primeiro, ("jovens grandes") ocorreu a $56 \mathrm{~m}$ de profundidade, fora da faixa costeira, na zona da isoterma de $22^{\circ} \mathrm{C}$, com $35,3 \%$ e $3,95 \mathrm{ml} / 1$; o segundo ("jovens grandes") a $65 \mathrm{~m}$ de profundidade, em ärea com temperatura de $18^{\circ} \mathrm{C}$, $34,4 \%$ e $5,41 \mathrm{ml} / 1$. No inverno, a influência da Corrente das Malvinas é identificada pelos mínimos de temperatura, ocorrendo águas costeiras de baixa salinidade, influenciadas principalmente por águas do Rio da Prata; o nücleo de maior abundância ("adultos pequenos") ocorreu diante de Albardão, a $45 \mathrm{~m}$ de profundidade, na região da isoterma de $12^{\circ} \mathrm{C}$, com salinidade de $33,2^{\circ} \%$ e $5,15 \mathrm{ml} / 1$. Na primavera, as isotermas são aproximadamente paralelas à costa; como as águas mais frias estão associadas a salinidades mais baixas, é evidente a influência das águas de origem subantártica, da Corrente das Malvinas. Neste período, verificou-se três núcleos de densidade elevada: um, diante de Sarita ( $32^{\circ} 27^{\prime} \mathrm{S}$ ) ("adultos pequenos") a $26 \mathrm{~m}$ de profundidade, na faixa de $14^{\circ} \mathrm{C}, 31,2^{\circ} \%$ e $5,22 \mathrm{ml} / 1$; outro, entre Chuí e Albardão ("adu1tos pequenos") a $38 \mathrm{~m}$ de profundidade, na isoterma de $11^{\circ} \mathrm{C}$, com salinidade de $32,2 \%$ e $5,86 \mathrm{ml} / 1$; e um terceiro, a $22 \mathrm{~m}$ de profundidade entre Maldonado e Chuí ("adultos pequenos"), na faixa costeira, a $13^{\circ} \mathrm{C}, 32,1^{\circ} \%$ e $5,86 \mathrm{ml} / 1$.

Assim, vemos que no verão há dois núcleos bem distintos: um, localizado entre 12-15 m em águas costeiras com temperatura elevada (24-25 ${ }^{\circ} \mathrm{C}$ ) e salinidade entre $31,9-33,3 \%$; e outro, a $90 \mathrm{~m}$ de profundidade com temperatura de $16,8^{\circ} \mathrm{C}$ e salinidade $35,8^{\circ} \%$ (äguas subtropicais). No outono, os núcleos localizam-se em profundidades entre 50-100 m, em regiões com temperaturas entre $18-22,5^{\circ} \mathrm{C}$ e salinidade entre $34,4-35,5 \%$, portanto, águas subtropicais com influência de àguas tropicais; no inverno e primavera, aproximam-se da costa, sendo encontrados entre $20-50 \mathrm{~m}$, em regiões com temperaturas entre $11-14^{\circ} \mathrm{C}$ e salinidades entre $31,1-33,2^{\circ} \%$, de águas subtropicais com forte influência da Corrente das Malvinas e da ärea do Estuário do Prata.

São evidentes movimentos perpendiculares à costa, como desenvolvimento dos indivíduos; os "jovens menores" localizam-se em regiões bem costeiras entre as isóbatas de 12-15 m; com o crescimento, na fase de "jovens pequenos", iniciam seu afastamento, sendo que na fasede "jovens grandes" habitam zonas entre as isóbatas de $50-100 \mathrm{~m}$; e, atingida a fase de "adultos pequenos", deslocam-se para regiões costeiras a profundidades entre 20-50 m. 
Além desse movimento ao largo da costa, a espécie realiza também migrações ao longo da costa, jā sugeridas por Alberdi \& Nani (1967), que acreditavam na possibilidade da espécie, cujo habitat trófico é Mar del Plata, reproduzir-se em latitudes menores, no sul do Brasil. Durante o verão, espécimes grandes (comprimentos mínimos de $187 \mathrm{~mm}$ ) permanecem na costa da Argentina, alimentando-se; no início do outono, iniciam deslocamentos para o norte, invadindo a costa uruguaia. Podemos verificar que nesse período começam a aparecer "adultos grandes" diante de Chuí, acentuando-se a entrada no inverno, quando ocorrem até $31^{\circ} \mathrm{S}$. Essa entrada reflete-se na distribuição de frequência de classes de comprimento, com aparecimento de modas para a direita nos histogramas, durante o inverno e primavera, o mesmo verificando-se quanto aos grupos de número de anéis. Esses indivíduos reproduzem-se principalmente na área entre $31-33^{\circ} \mathrm{S}$, durante o inverno-primavera, e retornariam para seu habitat trófico ainda na primavera. O movimento de "adultos grandes" verifica-se junto à costa.

Os indivíduos resultantes da desova permanecem na costa sul brasileira até atingirem o tamanho da primeira maturação sexual (2o ano de vida), ocorrendo estratificação ao longo da costa em relação à fase de desenvolvimento. Observa-se que os "jovens menores" ocorrem bem junto à costa (até $15 \mathrm{~m}$ ), no verão; os "jovens pequenos" ocorrem um pouco afastado da costa, no verãooutono, na região mais ao norte $\left(29-32^{\circ} \mathrm{S}\right)$; quando passam para a fase de "jovens grandes", tendem a afastar-se mais da costa, sendo que no verão ocorrem na altura de $30^{\circ} \mathrm{S}$, deslocando-se para o sul no outono; no inverno, jā atingiram a fase de "adultos pequenos", quando aproximam-se gradativamente da costa, sendo que na primavera já iniciam a migração para o sul, bem próxima desta. Alberdi \& Nani (1967) registram essa entrada de indivíduos menores na região de Mar del Plata, que se reflete no deslocamento para a esquerda das modas das distribuições de freqüência de classes de comprimento, por eles obtidas.

Vazzoler (1975) também verificou deslocamentos ao largo e ao longo da costa para $U$. canosai; constatou que no outono as maiores concentrações ocorrem entre 50-60 m, sendo rara a ocorrência de indivíduos na faixa costeira. Assinala que na primavera é nítido o deslocamento da espécie para o sul. Fica assim confirmada a existência de migrações trófica e genética de $U$. cano- 
sai ao longo da costa da Argentina, Uruguai e sul do Brasil.

Podemos delimitar três zonas dentro da ärea de distribuição da espécie: a) zona de alimentação (trófica), na região de Mar del Plata, onde provavelmente há alimento disponível; b) zona de reprodução, na região costeira sul do Brasil, entre $31-33^{\circ} \mathrm{S}$; c) zona de desenvolvimento, onde os indivíduos permanecem até atingirem a primeira maturação sexual, em regiões mais afastadas (entre $50-100 \mathrm{~m}$ ) da costa sul brasileira, entre as latitudes $29-34^{\circ} \mathrm{S}$.

Migrações similares são tambēm observadas em outras espécies de peixes marinhos, tais como em Sardinella brasiliensis do Atlântico Ocidental, cujos indivíduos nas fases iniciais de desenvolvimento realizam uma migração passiva para a área de alimentação dos jovens (criadouro); após esse período, quando os indivíduos iniciam a maturação $(165 \mathrm{~mm})$, deixam o criadouro dirigindo-se para a ārea de origem, onde permanecem e se reproduzem (RossiWongtschowski, 1974).

As populações de $M$. furnieri e $M$. ancylodon que ocupam a área entre 29$33^{\circ} \mathrm{S}$ também realizam migrações não condicionadas à alimentação e reprodução, determinadas por variações ambientais, acompanhando os deslocamentos da Convergência Subtropical (Vazzoler, 1963b; Vazzoler \& Santos, 1965; Santos \& Yamaguti, 1965).

Em sua migração genêtica, as fêmeas de U. canosai deixam o habitat trófico antes dos ruachos, ocorrendo o mesmo quando iniciam a migração trófica; isto provoca diferenças significativas na proporção dos sexos, durante o outono e inverno na costa sul do Brasil, por nós constatadas, e durante a primavera-verão na zona trófica (Alberdi \& Nani, 1967).

o tipo de desova parcelada, encontrado para $U$. canosai, foi constatado também para outras espécies que desovam ao sul de $29^{\circ} \mathrm{S}$, como Micropogon furnieri (Vazzoler, 1969; 1971), Macrodon ancylodon (Vazzoler, 1963a; Yamaguti, 1967), Merluccius mertuccius hubbsi (Angelescu et al., 1958; Ciechomski, 1967), e sugerida para outros Sciaenidae (Vazzoler, Zaneti \& Kawakami, 1973).

o tipo de desova é determinado pelas condições ecológicas durante a época de reprodução. As espécies que apresentam desova parcelada possuem capacidade de adaptação mais desenvolvida e fecundidade mais elevada, assegurando a conservação da espécie (Nikolsky, 1963). Em altas latitudes a estação 
de desova é frequentemente curta e os óvulos são liberados durante um período breve, de algumas horas (Clupeỉdeos) até alguns dias (Pleuronectiformes e Gadidea); em latitudes onde as estações do ano são menos marcadas, a desova ocorre durante um período bem mais prolongado, ou é intermitente através do ano, especialmente quando o tempo entre as gerações é somente de semanas ou meses (Hoar \& Randa11, 1969).

Estando o local de desova de $U$. canosai em uma ärea de transição, que sofre influência tanto de äguas da Corrente do Brasil como das Malvinas, dentro da zona de Convergência Subtropical, sem estações do anobemmarcadas, em condições ambientais lābeis, era de se esperar a ocorrência de desova parcelada (Nikolskii, 1969). Este mecanismo contribuiria para amenizar tanto a competição interespecífica como a intra-específica, nas primeiras fases de desenvolvimento, pois dentro da área em questão, ocorrem outras espécies de Sciaenidae que se reproduzem no mesmo local $\left(31-33^{\circ} \mathrm{S}\right.$ ) e na mesma época (inverno-primavera) que U. canosai (Vazzoler, 1971; Vazzoler, Zaneti \& Kawakami, 1973).

Para U. canosai, o estudo da relação entre fecundidade e outros parâmetros, mostrou estar esta, mais relacionada com o peso da gônada $\left(W_{g}\right)$ do que com o comprimento total $\left(\mathrm{L}_{t}\right)$ e peso total $\left(\mathrm{W}_{t}\right)$.

Dentro da mesma área, Vazzoler (1963a, 1969) estudando, respectivamente, $M$. ancylodon e $M$. furnieri, mostrou que a fecundidade, para ambas as espécies, é mais relacionada com o comprimento total; Ciechomski (1967) constatou que para Merluccius merluccius hubbsi, da costa argentina, a fecundidade estā mais relacionada ao peso total. Para Scomber japonicus marplatensis, foi verificado que a fecundidade nos indivíduos menores está mais relacionada ao comprimento, enquanto que para os espécimes maiores ela se relaciona mais como peso total (Ciechomski \& Capezzani, 1969). MacGregor (1957) observou, para Sardinops caerulae da Califórnia, que a fecundidade tem uma relação mais direta com o peso do corpo, sendo o mesmo encontrado para Sardinelza brasiliensis da costa brasileira (Vazzoler \& Rossi-Wongtschowski, 1976).

Com base nos resultados obtidos por Ciechomski\& Capezzani (op. cit.) para S. japonicus marplatensis, Vazzoler $(1963 a, 1969)$ para M. ancylodon e $M$. furnieri e Ciechomski (op. cit.) para M. merluccius hubbsi, foram calculados os níveis de fecundidade dessas espécies com o intuito de compará-los ao de 
U. canosai. Considerando que a fecundidade aumenta com o crescimento, estimou-se a fecundidade relativa em termos de número de óvulos por milímetro de comprimento para os tamanhos extremos da fase adulta. Para Scomber japonicus marplatensis, que apresenta desova total, encontramos nível de 382 óvulos/mm $\left(L_{t}=350\right)$ a 664 óvulos $/ \mathrm{mm}(450 \mathrm{~mm})$, inferior ao verificado para aquelas espécies que apresentam desova parcelada, como: M. ancylodon (161 óvulos/mm para $270 \mathrm{~mm}$ a 521 óvulos/mm para $400 \mathrm{~mm}$ ), M. furnieri (712 óvulos/mm para $400 \mathrm{~mm}$ a 1033 óvulos/mm para $600 \mathrm{~mm}$ ), U. canosai (274 óvulos/mm para $190 \mathrm{~mm}$ a 796 óvulos/mm para $300 \mathrm{~mm}$ ) e M. merluccius hubbsi (1132 óvulos/mm para 400 mm a 1934 óvulos/mm para $800 \mathrm{~mm}$, na desova de verão; 476 óvulos/mm para 400 $\mathrm{mm}$ a 1285 óvulos/mm para $800 \mathrm{~mm}$, na desova de inverno). Vemos que, dentre essas espécies, $U$. canosai è a que apresenta nível de fecundidade mais elevado.

Durante o processo de reprodução, as fêmeas consomem maior quantidade de energia que os machos, havendo necessidade de maior acúmulo de reserva por parte do organismo, que será revertida na formação de vitelo durante a ovogênese; assim, os pesos médios para uma mesma classe de comprimento são mais elevados para as fêmeas. A relação peso/comprimento, para U. canosai, mostrou-se mais elevada para as fêmeas, diferindo significativamente da dos machos.

Fêmeas e machos iniciam simultaneamente o processo de maturação (20 ano de vida), mas o concluem em períodos distintos (fêmeas, no 40 ano de vida; machos, no 50 ano de vida); o mesmo foi observado para $M$. furnieri dessa regiãc (Vazzoler, 1971).

Relacionando o crescimento da espécie ao seu desenvolvimento sexual pode-se observar que na fase jovem, antes dos indivíduos atingirem o comprimento do início da primeira maturação sexual, o crescimento em comprimento apresenta a taxa mais elevada, dentro do período de vida, enquanto o crescimento em peso é mínimo. No período intermediário, entre o instante do início da primeira maturação e aquele em que todos os indivíduos maturam, as taxas de incremento em comprimento e peso são semelhantes; no período final de vida, o crescimento em comprimento é mínimo, tendendo aos valores assintóticos, enquanto que o incremento em peso apresenta sua taxa máxima. Assim, observamos três "stanzas" no crescimento, tanto em comprimento quanto em peso, sendo que a "stanza" intermediária corresponde ao período em que os indivíduos 
da população desenvolvem maior atividade reprodutiva.

Para compararmos os resultados por nós obtidos com os de Alberdi \& Nani (1967) $\left(\mathrm{L}_{\infty}=415 \mathrm{~mm} ; \mathrm{W}_{\infty}=890 \mathrm{~g} ; \mathrm{k}=0,151 ; \mathrm{t}_{\mathrm{o}}=-2,8\right.$ anos $)$, calculamos as curvas de crescimento em comprimento e peso, para sexos grupados $\left(\mathrm{L}_{\infty}=427,07\right.$ $\mathrm{mm} ; \mathrm{W}_{\infty}=1054,0 \mathrm{~g} ; \mathrm{k}=0,1119 ; \mathrm{t}_{0}=-1,4691$ anéis), e constatamos que os valores estimados por aqueles autores sempre foram superiores aos por nós obtidos. Essa superestimativa se deve ao fato dos mesmos terem analisado apenas a fração adulta da população, em seu habitat trófico; os valores de $\mathrm{L}_{\infty}, \mathrm{W}_{\infty}$ e $k$ não são muito discrepantes, mas os de $t_{o}$ são bem distintos, No referido estudo, a formação de anéis em otólitos foi considerada como anual; os autores testaram a periodicidade de sua formação, mas não estimaram o tempo que decorre entre a formação de dois anéis consecutivos. Nosso trabalho fornece fortes evidências de que esses anéis são semestrais, de modo que a cada dois anéis corresponderia um ano de vida. Desse modo, transformando o valor de $t_{o}-(-2,8$ anos) obtido por Alberdi \& Nani (op. cit.), em termos de números de anéis, teríamos um valor para $t_{0}$ de $-5,6$ anéis.

Os anéis dos otólitos formam-se nos períodos verão-outono e inverno-primavera, podendo este último estar relacionado ao período de desova, não se constituinco em "anel verdadeiro". Anéis de desova ocorrem em otólitos do bacalhau do Ārtico (Gadus morhua) (Bagenal, 1974). Poinsard \& Troadec (1966) levantam hipótese semelhante para alguns Sciaenidae da costa da Āfrica.

Discutidos os aspectos mais relevantes relativos a ciclo de vida e bionomia de $U$. canosai, convém ressaltar que alguns problemas aqui levantados deverão merecer estudos mais completos e aprofundados, principalmente o estabelecimento do limite meridional e a confirmação do limite setentrional da distribuição da espécie, estudos relativos à alimentação, e esclarecimento dos fatores que determinam a formação semestral dos anéis nos otólitos.

\section{CONCLUSÕES}

0 estudo da bionomia e ciclo de vida de Umbrina canosai na plataforma continental entre Torres $\left(29^{\circ} 21^{\prime} \mathrm{S}\right.$ ) e Maldonado ( $34^{\circ} 54^{\prime} \mathrm{S}$ ), permite-nos con- 
cluir que:

1) A desova mais intensa ocorre na região entre $31-33^{\circ} \mathrm{S}$, em águas costeiras da plataforma que apresentam salinidades e temperaturas baixas e alto teor de oxigênio dissolvido, durante o inverno-primavera e verão.

2) A espécie apresenta desova parcelada, em dois lotes, como adaptação às condições ambientais lábeis da área de desova e mecanismo para amenizar a competição inter e intraespecífica nas primeiras fases de desenvolvimento;

3) Apresenta o nível de fecundidade mais elevado dentre as espécies estudadas, na mesma ärea. A fecundidade (F) está mais relacionada ao peso da gônada $\left(W_{g}\right)$ que ao peso total $\left(W_{t}\right)$ e comprimento total $\left(L_{t}\right)$; essas relações são expressas pelas equações:

$$
\begin{aligned}
& \widehat{\mathrm{F}}=23.755,70+14.544,68 \mathrm{~W}_{\mathrm{g}} \\
& \widehat{\mathrm{F}}=128,2 \mathrm{~W}_{\mathrm{t}}{ }^{1,2610} \\
& \widehat{\mathrm{F}}=0,0008 \mathrm{~L}_{\mathrm{t}}{ }^{3,4125} ;
\end{aligned}
$$

4) A entrada de indivíduos jovens para a população (recrutamento) se dá no período verão-outono, com maior intensidade no verão;

5) 0 processo de maturação sexual inicia-se no 29 ano de vida, quando as fêmeas apresentamum comprimento médio de $166,5 \mathrm{~mm}$ e os machos de 177 $\mathrm{mm}$.

6) 0 processo de maturação sexual completa-se em períodos distintos para ambos os sexos: para as fêmeas, ao atingirem $300 \mathrm{~mm}$, no 50 ano de vida, enquanto que, nos machos, completa-se aos $270 \mathrm{~mm}$, no 49 ano de vida;

7) Não foi constatada diferença significativa entre sexos, com relação ao crescimento. As equações abaixo expressam o crescimento em comprimento (Lt) e peso $\left(W_{t}\right)$, para fêmeas e machos:

$$
L_{t}=435,11\left[1-e^{-0,1103(t+1,6102)}\right]
$$

Fêmeas

$$
W_{t}=1189,0\left[1-e^{-0,1103(t+1,6102)}\right]^{3}
$$




$$
L_{t}=377,11\left[1-e^{-0,1588(t+0,7334)}\right]
$$

Machos

$$
W_{t}=774,5 \quad\left[1-e^{-0,1588(t+0,7334)}\right]^{3}
$$

Apesar da diferença não ser significativa, as fêmeas atingem comprimento e peso assintóticos maiores que os machos. Por esse motivo, mantivemos os valores separados para cada sexo;

8) Há evidências de que os anéis nos otólitos formam-se periodicamente, de 6 em 6 meses, um durante o verão-outono e outro no inverno-primavera. O maior número de anéis foi observado na primavera, também, para fêmeas (18 anēis);

9) A relação peso total/comprimento total difere significativamente entre sexos, sendo que para uma mesma classe de comprimento, as fêmeas apresentam peso médio mais elevado. Essa relação é expressa pelas equações :

$$
\begin{aligned}
& \text { Fêmeas } \quad W_{t}=0,000011 \mathrm{Lt}^{3,0449} \\
& \text { Machos } \quad \mathrm{W}_{\mathrm{t}}=0,000008 \mathrm{~L}_{\mathrm{t}}{ }^{3,1015}
\end{aligned}
$$

10) Verificou-se que os núcleos de maior densidade deslocam-se sazonalmente na plataforma, em estreito relacionamento com a penetração das águas subantärticas na costa do Rio Grande do Sul;

11) Ocorre estratificação na distribuição espacial das distintas fases de desenvolvimento, sendo que os indivíduos "jovens pequenos" e os "jovens grandes" são encontrados em posições mais afastadas da costa, enquanto os "jovens menores", juntamente com os adultos, ocorrem mais próximo à costa.

12) $U$. canosai é uma espécie de fauna temperada quente, que realiza migrações trófica, em direção a Mar del Plata (Argentina), na primavera, e genética, da zona trófica para a area de desova, na costado Rio Grande do Sul $\left(31-33^{\circ} \mathrm{S}\right)$, no outono. 


\section{SUMMARY}

The material analysed for the study about bionomics and life history of Umbrina canosai was collected in the continental shelf between $29^{\circ} 21^{\prime} \mathrm{s}$ (Torres, Brazil) and $34^{\circ} 54^{\prime} \mathrm{S}$ (Maldonado, Uruguay), during four cruises on board of the R/V. "Prof. W. Besnard" through 1972 and the following results were obtained:

1 - The densiest spawning area occurs in coastal shelf waters during winter/spring (August/November) at the region between $31-33^{\circ} \mathrm{S}$.

2 - "Partial spawners" occur, showing at least, two main patches over a spawning season.

3 - The highest fecundity level was observed if compared to the other species studied from the same area. Fecundity was more closely related to the gonadal weight than to the total weight and length.

4 - The entry of juveniles to the population occurs during summer/autumm (January/March).

5 - Sexual maturity begins, in both sexes, at the second year of life and it is attained when the males and females are 4 and 5 years old, respectively.

6 - No significantly statistical difference was observed between the two sexes, related to the growth rate, although females attained higher asymptotic length and weight values, than the males.

7 - The study of otoliths showed that rings were formed periodically every 6 months, in summer/autumm (January/May) and in winter/spring (August/November).

8 - The total weight/total length relationship differs significantly between the two sexes, the females presenting greater weight than the males of the same length group.

9 - It was verified that individual concentrations with highest density showed a seasonal displacement along the continental shelf. It was closely related to the inflow of the Subantarctic waters. 
10 - The smallest individuals as well as the adult ones occur near to the coast, while the young ones $(70-180 \mathrm{~mm})$ are found more distantly.

11 - The population studied undertakes trophic migrations towards Mar del Plata (Argentina) during spring (October/December) and genetic migrations from the zone towards the spawning area in Rio Grande do Sul (Brazil) during autumm (April/June) .

\section{AGRADEC IMENTOS}

Agradeço à Dra. Anna Emília A. de M. Vazzoler, minha orientadora, o incentivo, apoio e amizade irrestritos durante a elaboração deste trabalho, dando-me, constantemente, exemplo de elevado espírito científico, devotamento e dedicação ao trabalho.

À Fundação de Amparo à Pesquisa do Estado de São Paulo (FAPESP), pela bolsa concedida.

Ao Instituto Oceanogräfico da Universidade de São Paulo, pelo utilização do N/Oc. "Prof. W. Besnard", para coleta de material no Convênio GEDIP/ FPIOUSP, durante o PRGS II, e franquia de suas instalações e laboratórios em terra.

E a todos os que, direta ou indiretamente, auxiliaram-me na coleta, tomada de dados e arālise de material nas diversas fases de preparação deste trabalho.

\section{B IBLIOGRAF I A}

ALBERDI, P. G. \& NANI, A. 1967. Contribución al conocimiento de 1a biologia del pargo blanco Umbrina canosai Berg de la región de Mar del Plata (Argentina). CARPAS, liocum. téc. (10):1-36.

ANGELESCI, V.; GNERI, F. S. \& NANI, A. 1958. La merluza del mar argentino. Argentina, Secr. Mar., Serv. Hidrogr. Nav., H 1004:1-224.

BAGENAL, T. B., ed. $1974 . \quad$ The proceedings of an International Symposium on the ageing of fish. Surrey, England, Unwin Brothers, 234p. 
BENVEGNU, G. de Q. 1973. Relação dos peixes teleósteos. Publção esp. Inst. oceanogr., S Paulo, Parte I, (3):489-500.

BEVERTON, R. J. H. \& HOLT, S. J. 1957. On the dynamics of exploited fish populations. Fishery Invest., Lond. ser. 2, 19:1-553.

BOSCHI, E. 1964. Los peneidos de Brasil, Uruguay y Argentina. Boln Inst. Biol. mar., 7:37-42.

CIECHOMSKI, J. D. de 1967. Caracter del desove y fecundidad de la merluza argentina, Merluccius merluccius hubbsi, del sector bonaerense. Boln Inst. Biol. mar., 13:1-30.

\& CAPEZZANI, D. A. 1969. Fecundity of the Argentinean mackerel Scomber japonicus marplatensis. Marine Biol., 2(3): $277-282$.

CHRISTENSEN, J.M. 1964. Burning of otoliths, a technique for age determination of soles and other fish. J. Cons. perm. int. Explor. Mer, $29(1): 73-81$.

CLARK, F.N. 1934. Maturity of the California sardine (Sardina caerulae), determined by ova diameter measurements. Fish Bull. Calif., (42) :1-49.

FOWLER, H. W. 1942. A list of fishes known from the coast of Brazil. Archos Zool. Est. S Paulo, 3:115-184.

FURTAdo, V. V. 1973. Sedimentos de superfície de fundo. Publção esp. Inst. oceanogr. S Paulo, Parte II, (3) :83-115.

GILBERT, C. R. 1966. Western Atlantic sciaenid fishes of the genus Umbrina. Bul1. mar. Sci., 16(2):230-258.

HOAR, W. S. \& RANDALL, D. J., ed. 1969. Fish physiology. New York, Academic Press, v. 3.

HOWARD, G. V. \& LANDA, A. 1958. A study of the age, growth, sexual maturity, and spawning of the anchoveta (Cetengraulis mysticetus) in the Gulf of Panama. Bull. inter-Am. trop. Tuna Commn, 2(9):389-437.

IWAI, M. 1973a. Pesca exploratória e estudo biológico sobre camarão na costa centro-sul do Brasil do N/Oc. "Prof. W. Besnard" em 1969-1971. São Paulo, SUDELPA/Inst. oceanogr. Univ. S Paulo, 71p.

1973b. Pesquisa e estudo biológico dos camarões de valor comercial. Publção esp. Inst. oceanogr., S Paulo, Parte I, (3):501-534.

MacGREGOR, J. S. 1957. Fecundity of the Pacific sardine (Sardinops caerulae). Fishery Bull. Fish. Wildl. Serv. U. S., 57(121):427-449. 
MAGLIOCCA, A. 1973. Distribuição vertical de oxigênio dissolvido e alguns nutrientes. Publção esp. Inst. oceanogr., S Paulo, Parte III, (3): $1-41$.

MENEZES, N. A. 1971. Relação dos peixes ósseos coletados durante os cruzeiros do N/Oc. "Prof. W. Besnard" às costas do Rio Grande do Sul. Contrções Inst. oceanogr. Univ. S Paulo, sér. Ocean. biol., (25):44-60.

MIRANDA, L. B. de; LUEDEMANN, E. F. \& MIYAO, S. 1973. Distribuição da temperatura, salinidade e circulação geral em superfície. Publção esp. Inst. oceanogr., S Paulo, Parte II, (3):1-82.

NIKOLSKII, G. V. 1969. Theory of fish population dynamics. Edinburgh, Oliver \& Bloyd, 323p.

NIKOLSKY, G. V. 1963. The ecology of fishes. London, Academic Press, 352p.

POINSARD, F. \& TROADEC, J. P. 1966. Détermination de 1'âge par la lecture des otolithes chez deux espèces de sciaenidès Ouest - Africains (Pseudotolithus senegalensis) C. V. et P. typus (B1kr.). J. Cons. perm. int. Explor. Mer, 30(3):291-307.

RIBEIRO, A. M. 1915. Fauna brasiliense: Peixes-V (Eleutherobranchios Aspirophoros-Physoclisti). Archos Mus. nac., Rio de J., 17:1-668.

ROSSI-WONGTSCHOWSKI, C. L. D. B. 1974. Estudo das variações da relação peso total/comprimento total em função do ciclo reprodutivo e comportamento, de Sardinella brasiliensis (Steindachner, 1879) da costa brasileira entre as latitudes $23^{\circ} \mathrm{S}$ e $28^{\circ} \mathrm{S}$. Dissertação de mestrado. Universidade de São Paulo, Instituto de Biociências.

SADOWSKY, V. 1971. Relação dos peixes cartilaginosos capturados pe1o N/Oc. "Prof. W. Besnard" ao longo da costa do Estado do Rio Grande do Sul (Programa Rio Grande do Sul). Contrções Inst. oceanogr. Univ. S Paulo, sër. Ocean. biol., (25):40-43.

1973. Relação dos peixes cartilaginosos. Publção esp. Inst. oceanogr., S Paulo, Parte I, (3):483-488.

SANTOS, E. P. dos \& YAMAGUTI, N. 1965. Migração da pescada-foguete, Macrodon ancylodon. Bolm Inst. oceanogr., S Paulo, 14:115-124.

TRAVASSOS, H. \& PAIVA, M. P. 1957. Lista dos Sciaenidae marinhos brasileiros, contendo chave de identificação e proposta de "nomes vulgares oficiais". Bolm Inst. oceanogr., S Paulo, 8(1/2):139-165.

VAZZOLER, A. E. A. de M. 1963a. Sobre a fecundidade e a desova da pescada-foguete. Bolm Inst. oceanogr., S Paulo, 13(2):33-40.

1963b. Deslocamentos sazonais da corvina relacionados com as massas de ägua. Contrções Inst. oceanogr. Univ. S Paulo, sér. Ocean. biol., (5):1-8. 
VAZZOLER, A. E. A. de M. 1969. Mieropogon furnieri: fecundidade e tipo de desova. Bolm Inst. oceanogr., S Pau1o, 18:27-32.

1971. Diversificação fisiológica e morfolö-gica de Micropogon fumieri (Desmarest, 1822), ao sul de Cabo Frio, Brasil. Bolm Inst. oceanogr., S Paulo, 20(2):1-70.

\& SANTOS, E, P. dos 1965. Migração da corvina (Micropogon furnieri), na costa sul do Brasil. Bolm Inst. oceanogr., S Paulo, 14:115-128.

; ZANETI, E. M. \& KAWAKAMI, E. 1973: Estudo

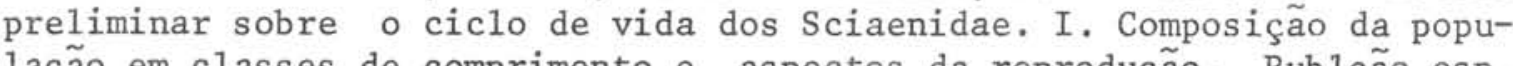
lação em classes de comprimento e aspectos da reprodução. Publção esp. Inst. oceanogr., S Paulo, Parte I, (3):239-291.

Sardinella brasiliensis: tipo de desova, fecundidade e potencial reprodutivo relativo. I. Área entre $23^{\circ} 40^{\prime} \mathrm{S}$ e $24^{\circ} 20^{\prime} \mathrm{S}$, Brasil. Bolm Inst. oceanogr., S Paulo, 25(2):131-155.

VAZZOLER, G. 1975. Distribuição da fauna de peixes demersais e ecologia dos Sciaenidae da plataforma continental brasileira, entre as latitudes $29^{\circ} 21^{\prime}$ S (Torres) e $33^{\circ} 44^{\prime} \mathrm{S}$ (Chuí). Bolm Inst. oceanogr., S Paulo, 24 (no ünico) : 85-169.

\& IWAI, M. 1971. Relatörio sobre prospecção e pesca exploratória na plataforma continental do Rio Grande do Sul. Contrções Inst. oceanogr. Univ. S Paulo, sér. Ocean. biol., (25):1-22.

; KAWAKAMI, E. \& ZANETI, E. M.

1973. Distribuição e abundância de peixes demersais. Publção esp. Inst. oceanogr., S Paulo, Parte I, (3) : 307-426.

YAMAGUTI, N. 1967. Desova da pescada-foguete, Macrodon ancylodon. Bolm Inst. oceanogr., S Paulo, 16:101-106.

-; ZANETI, E. M. \& KAWAKAMI, E. 1973. Estudo preliminar sobre o ciclo de vida dos Sciaenidae. II. Composição da população em classes de idade e aspectos do crescimento. Publção esp. Inst. oceanogr., S Paulo, Parte I, (3):293-306. 